\title{
La matriz de competitividad argentina: evolución de la inserción internacional del país ante la controversia de los recursos naturales ${ }^{1}$
}

\author{
Virginia Laura Fernández y Marcelo Luiz Curado
}

\section{Resumen}

Se analiza la evolución de la estructura de las exportaciones argentinas entre 1985 y 2010, utilizando la matriz de competitividad de Fajnzylber y Mandeng. En particular, se busca identificar vínculos entre el patrón de exportaciones del país, en el que predominan los recursos naturales, y la evolución de la estructura de diversos mercados: la Organización de Cooperación y Desarrollo Económicos (OCDE), el Mercado Común del Sur (MERCOSUR), los países en desarrollo de Asia y el mundo. Una de las principales conclusiones es que, aunque históricamente han sido los países desarrollados los que han determinado la primarización del patrón de exportaciones argentino, en las últimas décadas han sido los países en desarrollo de Asia los responsables de esto. En el MERCOSUR, por el contrario, se observa una mejora del patrón de exportaciones argentino, determinada, según se sugiere, por los acuerdos bilaterales entre la Argentina y el Brasil, en especial en el sector automotor.

\section{Palabras clave}

Competitividad, medición, exportaciones, estadísticas comerciales, mercados, OCDE, MERCOSUR, Asia Oriental, Argentina

\section{Clasificación JEL}

$$
\text { F10, O54, Q18 }
$$

\section{Autores}

Virginia Laura Fernández es Profesora en la Facultad de Ciencia Política y Relaciones Internacionales de la Universidad Nacional de Rosario (Argentina) y en el Departamento de Economía y el Máster Profesional en Desarrollo Económico de la Universidad Federal de Paraná (UFPR) (Brasil). Correo electrónico: virginialaurafernandez@ yahoo.com.ar.

Marcelo Luiz Curado es Profesor del Departamento de Economía y del Programa de Posgrado en Desarrollo Económico de la Universidad Federal de Paraná (Brasil) y Becario de Productividad en Investigación del Consejo Nacional de Desarrollo Científico y Tecnológico (CNPq) del Brasil. Correo electrónico: mlcurado@gmail.com.

\footnotetext{
Este artículo forma parte de la tesis doctoral que hizo la primera autora con la orientación del segundo autor. Una versión más sucinta recibió el premio 2015 al mejor artículo académico en el concurso Nuevas Ideas para el Desarrollo de la Asociación de Economía para el Desarrollo de la Argentina (AEDA). Se agradece la colaboración de Gabriel Porcile, de la Comisión Económica para América Latina y el Caribe (CEPAL) y la Universidad Federal de Paraná (UFPR), y el financiamiento de la Coordinación de Perfeccionamiento de Personal de Nivel Superior (CAPES) del Brasil.
} 


\section{Introducción}

Históricamente, las economías latinoamericanas se han caracterizado por tener estructuras productivas heterogéneas - donde coexisten sectores muy tecnificados con sectores primarios artesanales de baja productividad-, escasa diversificación productiva, dependencia del capital extranjero, poca participación de los trabajadores en la renta nacional, y una balanza comercial deficitaria o superavitaria, pero basada en la exportación de productos primarios y productos básicos.

Para un conjunto de autores latinoamericanos, como Raúl Prebisch (1949 y 1952), Celso Furtado (1962 y 1964), Aníbal Pinto (1960), Aldo Ferrer (1973), Fernando Fajnzylber (1983, 1988 y 1991) y otros, que contribuyeron al desarrollo del pensamiento estructuralista de la región que tuvo una gran influencia en la constitución y el fortalecimiento de la Comisión Económica para América Latina y el Caribe (CEPAL), dichas características han limitado el potencial de crecimiento y desarrollo de la región, ya que la inserción internacional de esta última y el lugar que ocupa en la división internacional del trabajo se definieron por la dependencia externa. Dicha dependencia se origina por el lado de la demanda, ya que la exportación de productos primarios y la determinación del precio de los productos básicos locales se definen en el mercado internacional, que es muy volátil e inestable. Además, la dependencia se agudiza con los flujos de capital externo, que actúan como una restricción externa al crecimiento de la inversión y el financiamiento en las economías de América Latina.

El proceso de industrialización y la diversificación de la pauta de las exportaciones, sobre todo entre 1950 y 1980, redujeron relativamente el problema de la dependencia externa, pero no lo resolvieron. Los desequilibrios comerciales y la vulnerabilidad externa permanecieron como fenómenos recurrentes que justificaron su presencia como tema de análisis económico cepalino. Bielschowsky (1998, pág. 24), por ejemplo, sustenta lo siguiente: "Con variaciones que se adaptan a los diferentes contextos del comercio mundial y a las diversas condiciones de financiamiento, el argumento de la vulnerabilidad externa acompaña a las cinco décadas de la reflexión cepalina".

Las transformaciones acontecidas en el comercio internacional a partir de los primeros años del siglo XXI, en especial la entrada de China y el proceso de reprimarización de la pauta exportadora de América Latina, dieron un nuevo impulso a las investigaciones en el área a nivel internacional2 ${ }^{2}$. Es en este contexto que se enmarca la contribución de este trabajo.

En este artículo se busca analizar las particularidades del patrón de exportaciones y de competitividad internacional de la Argentina en el nuevo orden mundial, caracterizado por el cambio radical de los patrones mundiales de producción, consumo e intercambio comercial. Asimismo, se destaca la relevancia de utilizar un cuerpo teórico propio -latinoamericano- para interpretar el proceso de crecimiento y desarrollo de la Argentina.

El objetivo principal es analizar el patrón de exportaciones argentino en el período de 1985 a 2010, utilizando la matriz de competitividad de Fajnzylber y Mandeng. Específicamente, se busca identificar vínculos entre la estructura de las exportaciones del país y la evolución de la estructura de mercado de diversos destinos, a saber, la Organización de Cooperación y Desarrollo Económicos (OCDE), el Mercado Común del Sur (MERCOSUR), los países en desarrollo de Asia y el mundo. Por último, se pretende establecer causalidades entre un patrón de exportaciones en el que predominan los recursos naturales y la competitividad.

En la metodología de análisis se combinan elementos conceptuales de la matriz de competitividad y del Análisis de la Competitividad de los Países (CAN), que Fajnzylber y Mandeng expusieron en la Revista de la CEPAL en 1991 (Fajnzylber, 1991; Mandeng, 1991a). Se utiliza como

\footnotetext{
2 Solo para citar un ejemplo de la importancia de este debate, en 2015 la Latin American Perspectives (2015) dedicó un número exclusivo a la discusión sobre los efectos que China estaba provocando en América Latina, con foco en las relaciones comerciales y en la discusión sobre el impacto de la reprimarización de la pauta exportadora latinoamericana.
} 
fuente la base de datos TradeCAN de la CEPAL, que abarca más del 90\% del comercio internacional y contiene información sobre 73 países. A pesar de que dicha base de datos surgió de aquel trabajo conjunto llevado a cabo por los autores mencionados, esta no ha sido muy utilizada para estimar la competitividad de los países en los últimos años. Por ese motivo, la propuesta de utilizar esta metodología implica un esfuerzo adicional de investigación y operacionalización del sistema.

En el artículo se presenta lo siguiente: los conceptos y el modelo de la matriz de competitividad de Fajnzylber y Mandeng en el marco de la discusión teórica estructuralista sobre la dependencia respecto de los recursos naturales (sección II); un análisis empírico de la matriz de competitividad argentina durante el período 1985-2010 (sección III), y reflexiones sobre la relevancia de los recursos naturales en la evolución del patrón de exportaciones argentino y la influencia de cada mercado en dicho patrón (sección IV).

\section{Matriz de competitividad de Fajnzylber y Mandeng}

En 1991, Fernando Fajnzylber y Ousmène Mandeng analizaron la relación entre el patrón de exportaciones y la competitividad de los países. El objetivo era contribuir con herramientas al diseño de estrategias y políticas nacionales y sectoriales en las economías de América Latina, y analizar la estructura de las exportaciones de varios países, principalmente latinoamericanos, así como el nivel de competitividad de estos, en el decenio 1979-1988.

Antes de presentar la metodología, expondremos cuatro puntos que Fajnzylber destacó sobre el vínculo entre la competitividad de los países y los recursos naturales, que son relevantes para nuestro análisis. El primero es que, de un total de 51 países analizados, el patrón de exportaciones de los países ganadores (los que ganaron espacio en el mercado de la OCDE entre 1979 y 1988) estaba menos basado en los recursos naturales que el de los perdedores.

El segundo punto es que había países miembros de la OCDE que mantenían una inserción internacional superavitaria en actividades vinculadas con los recursos naturales, pero deficitaria en el sector manufacturero, y que en dichos países, como el Canadá, los Estados Unidos, Noruega, Dinamarca y el Reino Unido, el progreso técnico de la industria manufacturera estaba inexorablemente ligado a los recursos naturales y era potenciado por estos.

El tercer elemento que Fajnzylber puso de relieve es que América Latina no era el principal oferente de recursos naturales de la OCDE ni del mundo. En 1989, la participación de la región en las importaciones de recursos naturales de la OCDE era del 10\% y en las de manufacturas basadas en recursos naturales del 5\% (Fajnzylber, 1991, pág. 171).

Finalmente, el autor destaca que, durante el período analizado, en la OCDE se redujo la participación de las importaciones de manufacturas basadas en recursos naturales, que pasaron de representar un tercio del total a representar un cuarto. Según Fajnzylber, esto "refleja y confirma la tendencia a la reducción del uso de recursos naturales y particularmente de energía en la actividad económica de los países desarrollados" (Fajnzylber, 1991, pág. 169). Este aspecto, en una concepción de competitividad condicionada por la demanda, preocupaba al autor y lo incitaba a proponer estrategias de política económica para modificar el patrón de exportaciones de las economías de América Latina.

Estas observaciones serán confrontadas con los datos más actuales acerca de la Argentina. Cabe destacar que hubo un elemento que no fue considerado por Fajnzylber (ni podría haberlo sido, ya que él falleció en 1991) y que es relevante para el análisis del comportamiento del comercio 
internacional en el período objeto de nuestro análisis: el ascenso de China, la India y otras economías emergentes en el mercado mundial de la producción y el consumo. Esto revertiría la tendencia hacia el estancamiento de la demanda de recursos naturales básicos y manufacturados.

\section{Metodología}

En la metodología que Fajnzylber y Mandeng utilizaron para medir la competitividad de un país se analizan estrictamente los datos de la estructura de exportaciones de este con relación a la estructura de las importaciones de la OCDE. Los países se definen como ganadores o perdedores, según que su participación en el mercado de la OCDE haya aumentado o disminuido, y, a partir de allí, se aplica la matriz de competitividad para verificar en qué rubros su participación en el mercado aumentó o disminuyó. Es en este marco que la discusión sobre los recursos naturales, la tecnología y la matriz productiva de un país adquiere relevancia.

Por ejemplo, tomemos el caso de dos países que interesan en el análisis, a saber, la Argentina y el Brasil, este último principal socio comercial del primero. En el período analizado por Fajnzylber, la participación de la Argentina en el mercado de la OCDE se redujo del 0,4\% al 0,25\%, motivo por el cual se considera que el país es perdedor. En cambio, la participación del Brasil aumentó un 20\% y, en 1988, alcanzó una cuota de mercado del 1,19\%. Por este motivo se lo incluye entre los países ganadores (Fajnzylber, 1991, págs. 154, 155).

Luego de clasificar los países en ganadores y perdedores, Fajnzylber analiza la composición de sus exportaciones, combinando los conceptos de eficiencia y posicionamiento ${ }^{3}$. Los autores llaman matriz de competitividad a esa combinación, que permite identificar cuatro situaciones en el patrón de las exportaciones:

i) Situación óptima, que supone un posicionamiento favorable y una eficiencia alta. Las exportaciones en esta situación corresponden a la parte del comercio en que el país se especializa, o sea, tiene una ventaja productiva sobre el resto de los oferentes y, al mismo tiempo, a rubros que son dinámicos entre las importaciones de la OCDE. Cuando una proporción grande de las exportaciones de un país se encuentra en situación óptima, significa que este es competitivo desde el punto de vista productivo y que se especializa en sectores que están ganando espacio en el mercado de la OCDE.

ii) Situación de vulnerabilidad, que supone un posicionamiento desfavorable y una eficiencia alta. Que haya exportaciones en esta situación significa que el país se está especializando en rubros que son poco dinámicos en el mercado de la OCDE. En términos precisos, remite a una situación presente (correspondiente al período analizado) en que se obtienen resultados positivos, pero podría indicar perspectivas negativas para los períodos futuros, si la decadencia de la demanda de esos rubros se reforzara con el tiempo. En el caso de América Latina, donde los recursos naturales determinan el patrón de especialización comercial, una caída sostenida de la demanda de estos evidenciaría la vulnerabilidad de sus exportaciones.

iii) Situación de oportunidades perdidas, que supone un posicionamiento favorable y una eficiencia baja. Las oportunidades perdidas remiten a las exportaciones cuyos rubros se están dinamizando en la demanda de la OCDE, pero respecto de las cuales el país analizado pierde cuota de mercado con relación a los demás oferentes. Así, la estructura de las exportaciones del país en esos rubros no se estaría adaptando a los cambios de la estructura importadora de la OCDE. En este caso también es pertinente analizar si la tendencia creciente de las importaciones de esos rubros es coyuntural o si se fortalecerá con el tiempo. En este último caso, la estrategia del país debería ser alcanzar los niveles de competitividad que ya tuvo o mejorarlos.

\footnotetext{
3 Mandeng aborda al posicionamiento a partir de la atracción del mercado, y la eficiencia desde la óptica de la especialización y la adaptabilidad. Por motivos de simplicidad, seguiremos la denominación de Fajnzylber.
} 
iv) Situación de retirada, que supone un posicionamiento desfavorable y una eficiencia baja. Esta situación refleja los rubros de exportación en que el país perdió cuota de mercado y cuya demanda por parte de la OCDE está declinando. Esta clasificación no es negativa en todos los casos, ya que podría estar mostrando una situación de adaptabilidad de la estructura de las exportaciones del país a los cambios en las importaciones de la OCDE.

Los datos de la matriz de competitividad de la Argentina y el Brasil entre 1979 y 1988 se muestran en el cuadro 1.

\section{Cuadro 1}

Argentina y Brasil: matriz de competitividad, 1979-1988

(En porcentajes del total de exportaciones)

\begin{tabular}{lcccc}
\hline País & Situación de vulnerabilidad & Situación óptima & $\begin{array}{c}\text { Situación de } \\
\text { oportunidades perdidas }\end{array}$ & Situación de retirada \\
\hline Argentina & 28 & 13 & 22 & 37 \\
\hline Brasil & 46 & 41 & 8 & 4 \\
\hline
\end{tabular}

Fuente: F. Fajnzylber, "Inserción internacional e innovación institucional", Revista de la CEPAL, № 44 (LC/G.1667-P), Santiago, Comisión Económica para América Latina y el Caribe (CEPAL), 1991.

El Brasil, país ganador, posee un elevado porcentaje de exportaciones en situación óptima, y un bajo porcentaje en situación de retirada y de oportunidades perdidas. En el caso de la Argentina, país perdedor de mercado, ocurre justamente lo contrario. En el gráfico 1 se exponen las matrices de ambos países en un gráfico radial.

\section{Gráfico 1}

Argentina y Brasil: matriz de competitividad, 1979-1988

(En porcentajes de las exportaciones)

Situación de vulnerabilidad

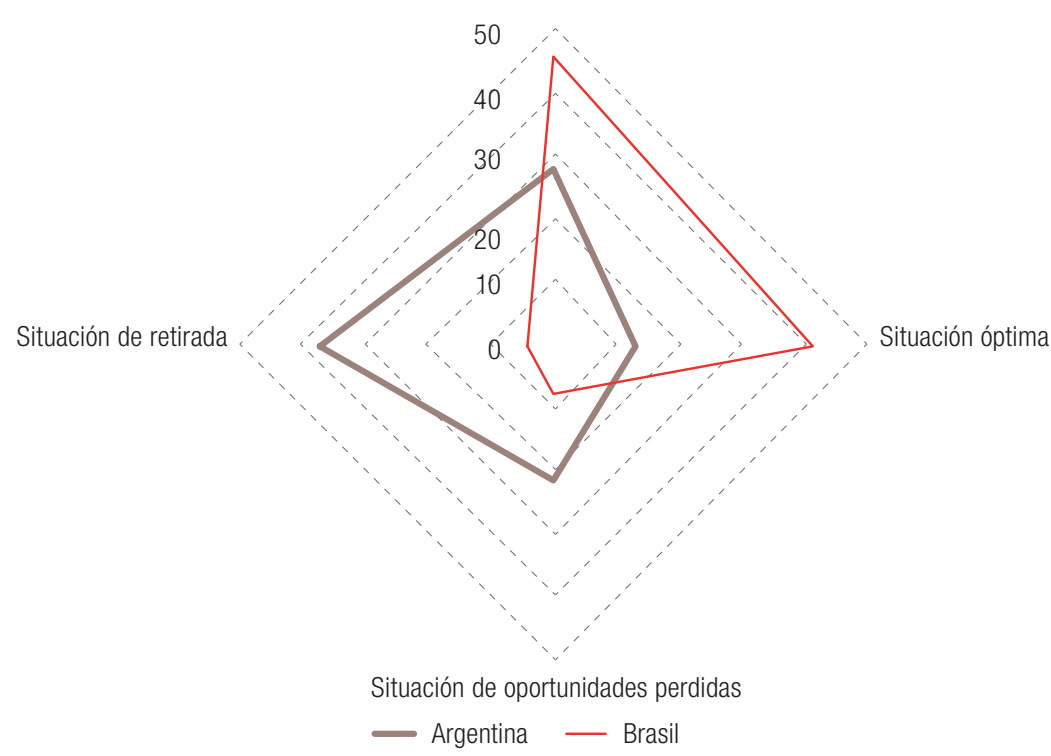

Fuente: Elaboración propia, sobre la base de F. Fainzylber, "Inserción internacional e innovación institucional", Revista de la CEPAL, № 44 (LC/G.1667-P), Santiago, Comisión Económica para América Latina y el Caribe (CEPAL), 1991. 
Finalmente, como ya se ha mencionado, el progreso técnico incide integralmente en la competitividad. Lo hace por la vía del posicionamiento, ya que el dinamismo está asociado al contenido tecnológico de los productos en cuanto al diseño y la fabricación, y por la vía de la eficiencia productiva, a través de la capacidad sistémica y organizativa de la producción a niveles de frontera internacional, que se asemeja a la productividad de los competidores en el mercado internacional ${ }^{4}$.

A continuación se analiza la composición de las exportaciones de la Argentina y el Brasil. Como se ha sugerido, los países cuyas exportaciones se concentran en los recursos naturales tienden a ser perdedores de mercado. En cambio, aquellos en cuya estructura predominan las manufacturas no basadas en recursos naturales suelen ser ganadores. Esto no difiere de lo que ocurre en el caso de los dos países mencionados (véase el cuadro 2).

\section{Cuadro 2}

Argentina y Brasil: estructura de las exportaciones, 1988

(En porcentajes)

\begin{tabular}{lcccc}
\hline & Recursos naturales & Energía & \multicolumn{2}{c}{ Manufacturas } \\
\cline { 4 - 5 } & 36 & 3 & $\begin{array}{c}\text { Basadas en } \\
\text { recursos naturales }\end{array}$ & $\begin{array}{c}\text { No basadas en } \\
\text { recursos naturales }\end{array}$ \\
\hline Argentina & 30 & 3 & 43 & 18 \\
\hline Brasil & 30 & 29 & 38 \\
\hline
\end{tabular}

Fuente: F. Fajnzylber, "Inserción internacional e innovación institucional", Revista de la CEPAL, № 44 (LC/G.1667-P), Santiago, Comisión Económica para América Latina y el Caribe (CEPAL), 1991.

\section{Modelo}

El modelo propuesto por Mandeng (1991a y 1991b) deriva de la adaptación del análisis de la participación constante de mercado (Magee, 1975), en el que se analiza la competitividad de las empresas frente al mercado mundial. Dicho análisis se adaptó de forma inédita para describir e identificar cambios de la competitividad y la especialización de los países en el comercio mundial.

Se parte de una ecuación única del análisis de la participación constante de mercado, y se la reduce a un enfoque bidimensional (competitividad sectorial y adaptabilidad al mercado) ${ }^{5}$. El análisis se basa en el concepto y la metodología del análisis de la competitividad de los países, según los cuales la posición global de una economía está determinada por su competitividad sectorial y por la capacidad que tenga para adaptarse a la evolución de la estructura del mercado. En el enfoque se supone que el mercado tiene una estructura atomística y que cada sector es tan pequeño como para no influenciar el patrón global de las importaciones (Mandeng, 1991a, pág. 27).

Entonces, la participación total de un país $\left(S_{j}\right)$ en un momento determinado será igual al producto ponderado de la participación de sus importaciones de determinado grupo sectorial $\left(s_{i j}\right)$ y la relevancia de dicho grupo en las importaciones del mercado $\left(s_{i}\right)$ :

$$
S_{j}=\sum_{i=1}^{n} \frac{M_{i j} M_{i}}{M_{i} M}=\sum_{i=1}^{n} s_{i j} s_{i}
$$

\footnotetext{
4 El posicionamiento y la eficiencia pueden entenderse como variables representativas de las perspectivas keynesiana y schumpeteriana, respectivamente, sobre la dinámica de las exportaciones de los países.

5 En el análisis de la participación constante de mercado se consideran cuatro elementos que afectan la evolución de la participación global de un país en el mercado: i) el crecimiento del comercio mundial; ii) el crecimiento diferencial por productos; iii) el crecimiento diferencial del mercado, y iv) un residuo o factor competitivo.
} 
donde:

$i$ : es un producto o grupo sectorial, denominado grupo,

$j$ : es un país, y

$M$ : son las importaciones totales de la OCDE.

Se determinan las variaciones de $S_{j}$ en el tiempo para evaluar la orientación de la competitividad con relación a las estructuras cambiantes del mercado. La hipótesis de participación constante requiere que $\Delta S_{j}$ sea igual a 0 , y la evolución diferencial de los grupos (o su atractivo mercantil) se obtiene por las variaciones de $s_{i}$.

A continuación se elabora una matriz de competitividad de dos filas y dos columnas basada en la ecuación (1), en cuyo eje horizontal se mide la evotlución de los grupos $\left(\Delta s_{i}\right)$ y en cuyo eje vertical se mide la evolución del país ( $\Delta s_{i j}$ ) (véase el diagrama 1). Así, se considera que un grupo es ascendente cuando $\Delta s_{i}$ es $\geq 0$, y que un país es competitivo en determinado grupo cuando $\Delta s_{i j}$ es $\geq 0$.

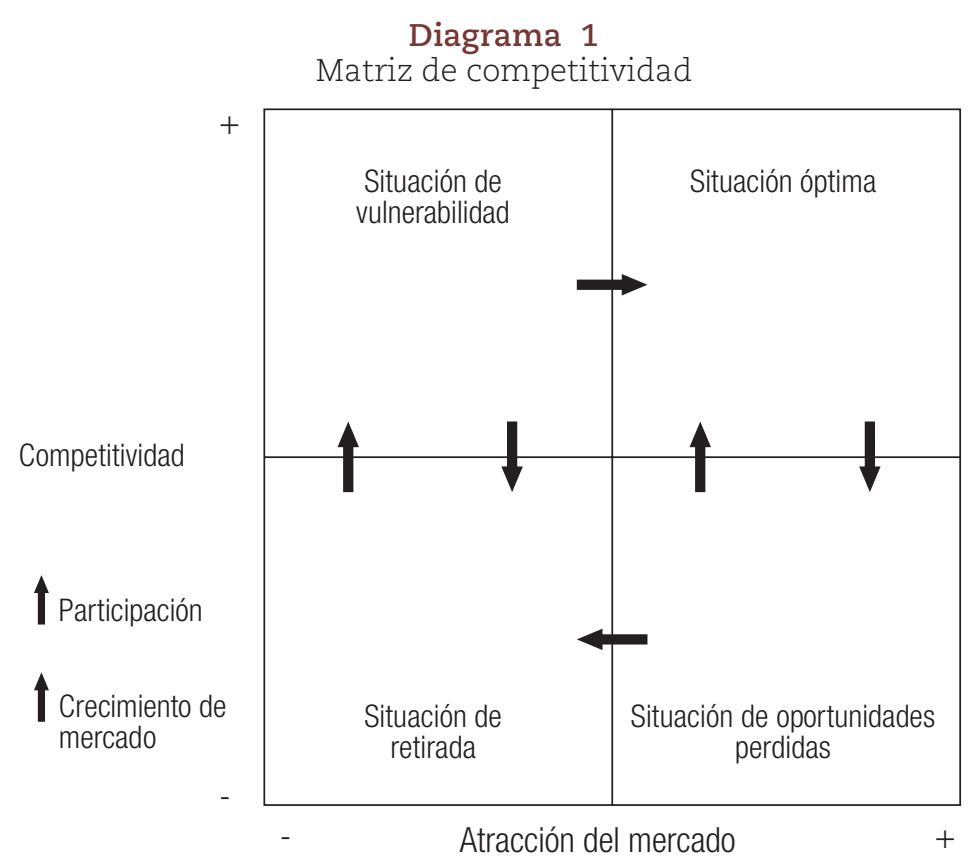

Fuente: O. J. Mandeng, "Competitividad internacional y especialización”, Revista de la CEPAL, № 45 (LC/G.4687-P), Santiago, Comisión Económica para América Latina y el Caribe (CEPAL), 1991.

Nota: Para otorgar más claridad y dar seguimiento a la terminología de Fajnzylber, se han utilizado las expresiones empleadas por este autor, en reemplazo de los títulos de los cuadrantes del diagrama original, que eran (desde arriba a la izquierda, en el sentido de las manecillas del reloj): Estrellas menguantes, Estrellas nacientes, Oportunidades perdidas y Retrocesos.

En la matriz de competitividad se resumen las situaciones en las que se puede encontrar cada país:

- Situación óptima: grupos ascendentes en que el país gana participación de mercado.

- Situación de vulnerabilidad: grupos descendentes en que el país gana participación de mercado.

- Situación de oportunidades perdidas: grupos ascendentes en que el país pierde participación de mercado.

- Situación de retirada: grupos descendentes en que el país pierde participación de mercado. 
Además, podemos conocer la importancia relativa de cada posición competitiva de la matriz a través de la estructura comercial del país. Para esto se define la variable $c_{i j}$, que mide la contribución de cada grupo en un país determinado, donde $c_{i j}=M_{i j} / M_{j}$. Las variaciones de $c_{i j}$ muestran la diversificación de la estructura comercial, donde $\Delta c_{i j} \geq 0$ significa que la contribución del grupo crece, y $\Delta c_{i j}<0$ significa que la contribución disminuye.

Se emplea asimismo una variable $k$ que representa la especialización de mercado. Ella permite relacionar la contribución de cada grupo en un país con la estructura de las importaciones de la OCDE:

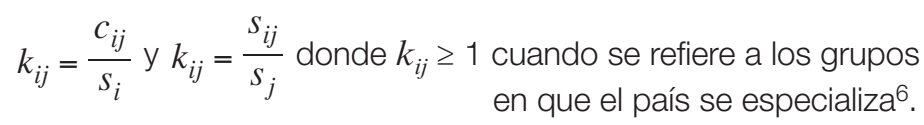

De esta manera, las variaciones de $k_{i j}$ están determinadas por las variaciones de $c_{i j}$ y $s_{i}$, y reflejan el grado en que la estructura del comercio se aleja de la estructura de las importaciones de la OCDE o se acerca a ella: $\Delta k_{i j}$ es $\geq 0$ en el primer caso, y $\Delta k_{i j}$ es $<0$ en el segundo.

$$
\Delta c_{i j} \geqq \Delta s_{i} \geqq \Delta k_{i j} \geqq 0
$$

Así, $\Delta k$ representa la interacción entre los cambios de la estructura comercial de un país y la evolución de la estructura del mercado: $k_{i n c}$ corresponde a los grupos ascendentes y $k_{d e c}$ a los grupos descendentes. Además, $\Delta k$ puede reflejar la evolución de la competitividad sectorial frente a los resultados globales del comercio del país $\left(S_{j}\right)$.

Finalmente, la adaptabilidad total de un país al mercado, $K_{j}$, se expresa por la especialización global y la competitividad de una economía frente a la evolución del mercado:

$$
K_{j}=\frac{k_{\text {iincj }}}{k_{\text {idecj }}} \text { y } K_{j}=\frac{s_{\text {iinci }}}{s_{\text {ideci }}}
$$

Lo anterior se deriva de $\left(M_{\text {iincj }} / M_{j}: M_{\text {inc }} / M\right):\left(M_{\text {idecj }} / M_{j}: M_{\text {idec }} / M\right)=\left(M_{\text {incj }} / M_{\text {inc }}\right):\left(M_{\text {idecj }} / M_{\text {idec }}\right)=$ $\left.s_{\text {iincj }} / s_{\text {idecj }}\right)$. Se concluye que $K_{j}$ admite dos criterios de interpretación. En el primero se opone la participación de los grupos ascendentes y los descendentes, y $K_{j}>1$ significa que la competitividad absoluta es mayor en los grupos ascendentes que en los descendentes. En el segundo se combina la orientación de mercado de los grupos ascendentes y los descendentes, y $K_{j}<1$ significa que hay una especialización relativamente mayor en los grupos descendentes que en los ascendentes.

En estos casos, la evolución de $K$ en el tiempo, $\Delta K=K_{j}^{1} / K_{j}^{0}$, representa una de las siguientes dos opciones: i) la redistribución de la competitividad de un país respecto de la evolución del mercado, o ii) el cambio en la especialización respecto del crecimiento del mercado.

Según el autor, las variaciones de $K$ revelan la ponderación de los grupos sectoriales, que aumenta o disminuye dentro de la estructura nacional de comercio, y describen cómo los países compiten y se especializan a nivel mundial en lo que respecta a la evolución del mercado.

Para concluir, el modelo tiene tres limitaciones que coinciden con las del análisis de la participación constante de mercado. La primera se refiere a la desagregación sectorial, que es típica en cualquier problema de agregación. La segunda tiene que ver con el período seleccionado y podría

\footnotetext{
${ }^{6}$ La variable $k$ sigue el índice de ventaja comparativa revelada de Balassa (1965). Dada la ecuación $k=M_{i j} / M_{j}: M_{i} / M$, si
} cambiamos los denominadores, alcanzamos la siguiente ecuación: $k=M_{i j} / M_{i}^{\star} M / M_{j}=s_{i j} / S_{j}$. 
resolverse utilizando números índices. Asimismo, el autor plantea que el modelo es sensible a este aspecto. Y la tercera limitación se basa en el mercado de referencia.

En el estudio de Fajnzylber y Mandeng, la desagregación se efectuó considerando la Clasificación Uniforme para el Comercio Internacional (CUCl, revisión 2), en la que se clasifican 239 grupos sectoriales a la altura de tres dígitos. El período considerado fue el de 1979-1988 y el mercado de referencia fue la OCDE.

En este artículo se utiliza la misma desagregación sectorial, aunque en algunos casos se sigue la clasificación de Mandeng (1993) y se reagrupa en ramas, a saber: recursos naturales; energía; manufacturas basadas en recursos naturales, y manufacturas no basadas en recursos naturales. El período de análisis se divide en cuatro. Los años que transcurren entre los dos extremos reflejan la serie completa de la base de datos TradeCAN ${ }^{7}$. Los subperíodos se relacionan con el preludio de la conformación del MERCOSUR (1985-1990), la implementación del consenso de Washington y el Plan de Convertibilidad (1990-2000), la expansión de los países asiáticos como consumidores y oferentes mundiales (2000-2007), y la crisis mundial de 2007-2008 (2007-2010). Los mercados de referencia son el mundo, la OCDE ${ }^{8}$, el MERCOSUR ${ }^{9}$ y los países en desarrollo de Asia ${ }^{10}$.

\section{Construcción de la matriz de competitividad argentina}

En esta sección se presenta la relación entre la estructura comercial argentina y la estructura de los mercados. Primero se caracteriza el mercado mediante la lectura de datos. Luego se analiza la estructura de las exportaciones argentinas hacia cada destino. Después se presentan los diez primeros rubros de exportación, para conocer las especificidades de dicha estructura comercial. Finalmente se construye la matriz de competitividad del país.

\section{Estructura de los mercados}

Una característica común de los mercados analizados es que, a lo largo de los períodos, la demanda de recursos naturales y manufacturas de bajo valor agregado es poca en términos proporcionales (véase el cuadro 3). Y si bien no se advierten alteraciones radicales en la estructura de la demanda de los mercados del mundo y la OCDE, es evidente que las estructuras de mercado de los países en desarrollo de Asia y el MERCOSUR presentaron dinámicas propias que merecen la atención, incluso porque, como se verá, influyeron radicalmente en la estructura comercial argentina.

\footnotetext{
7 La base de datos TradeCAN está siendo actualizada. En el momento de la investigación, los últimos datos oficiales disponibles eran de 2010.

8 Actualmente, los países miembros de la OCDE son 34. Sin embargo, para mantener cierta coherencia analítica y posibilitar una comparación más fiel, en este trabajo solo se consideran los 24 países que la integraban en el análisis de Fajnzylber y Mandeng, a saber: Alemania, Australia, Austria, Bélgica, Canadá, Dinamarca, España, Estados Unidos, Finlandia, Francia, Grecia, Irlanda, Islandia, Israel, Italia, Japón, Luxemburgo, Noruega, Nueva Zelandia, Holanda, Portugal, Reino Unido, Suecia y Suiza.

9 EI MERCOSUR está integrado por la Argentina, el Brasil, el Paraguay y el Uruguay.

${ }^{10}$ Los países en desarrollo de Asia son los siguientes: Arabia Saudita, China, Chipre, Filipinas, Hong Kong (Región Administrativa Especial de China), India, Indonesia, Jordania, Macao (Región Administrativa Especial de China), Malasia, Nepal, Omán, Pakistán, Qatar, República Árabe de Siria, República de Corea, Singapur, Tailandia y Turquía.
} 


\section{Cuadro 3}

OCDE, MERCOSUR, países en desarrollo de Asia y mundo: estructura de mercado de las importaciones, por sector, 1985-2010a (En porcentajes)

\begin{tabular}{|c|c|c|c|c|c|c|c|c|c|c|}
\hline \multirow{2}{*}{ Sector } & \multicolumn{5}{|c|}{ Mundo } & \multicolumn{5}{|c|}{ OCDE } \\
\hline & 1985 & 1990 & 2000 & 2007 & 2010 & 1985 & 1990 & 2000 & 2007 & 2010 \\
\hline Recursos naturales & 16,33 & 14,54 & 10,31 & 10,43 & 11,34 & 16,11 & 14,56 & 10,48 & 10,18 & 10,98 \\
\hline Agricultura & 13,40 & 11,96 & 8,81 & 7,91 & 8,71 & 13,27 & 12,17 & 9,15 & 8,42 & 9,39 \\
\hline Fibras textiles, minerales y metales & 2,93 & 2,58 & 1,51 & 2,52 & 2,63 & 2,84 & 2,39 & 1,32 & 1,75 & 1,59 \\
\hline Energía & 17,35 & 9,71 & 9,31 & 10,21 & 9,93 & 17,82 & 9,78 & 8,94 & 10,57 & 10,35 \\
\hline Manufacturas & 64,86 & 73,98 & 77,85 & 71,77 & 70,05 & 64,54 & 73,82 & 77,48 & 71,47 & 69,51 \\
\hline $\begin{array}{l}\text { Manufacturas basadas en } \\
\text { recursos naturales }\end{array}$ & 5,67 & 5,79 & 4,78 & 5,02 & 4,78 & 5,89 & 5,85 & 4,75 & 4,81 & 4,16 \\
\hline $\begin{array}{l}\text { Manufacturas no basadas } \\
\text { en recursos naturales }\end{array}$ & 59,19 & 68,20 & 73,07 & 66,74 & 65,28 & 58,66 & 67,97 & 72,72 & 66,66 & 65,35 \\
\hline Otros & 1,47 & 1,78 & 2,53 & 7,60 & 8,68 & 1,54 & 1,84 & 3,10 & 7,78 & 9,16 \\
\hline \multirow{2}{*}{ Sector } & \multicolumn{5}{|c|}{ MERCOSUR } & \multicolumn{5}{|c|}{ Países en desarrollo de Asia } \\
\hline & 1985 & 1990 & 2000 & 2007 & 2010 & 1985 & 1990 & 2000 & 2007 & 2010 \\
\hline Recursos naturales & 16,97 & 15,41 & 9,52 & 7,74 & 7,16 & 16,01 & 13,10 & 9,37 & 10,50 & 12,00 \\
\hline Agricultura & 13,58 & 11,11 & 7,88 & 5,56 & 5,73 & 12,53 & 9,61 & 7,07 & 5,87 & 6,73 \\
\hline Fibras Textiles, minerales y metales & 3,40 & 4,29 & 1,64 & 2,18 & 1,43 & 3,49 & 3,49 & 2,31 & 4,63 & 5,27 \\
\hline Energía & 34,12 & 23,18 & 11,54 & 9,92 & 7,91 & 14,81 & 8,82 & 11,50 & 10,36 & 10,26 \\
\hline Manufacturas & 48,83 & 61,33 & 78,80 & 73,50 & 77,60 & 67,75 & 76,80 & 78,30 & 72,41 & 70,18 \\
\hline $\begin{array}{l}\text { Manufacturas basadas en } \\
\text { recursos naturales }\end{array}$ & 2,90 & 3,31 & 2,71 & 3,05 & 2,56 & 4,89 & 6,26 & 5,61 & 5,84 & 6,53 \\
\hline $\begin{array}{l}\text { Manufacturas no basadas } \\
\text { en recursos naturales }\end{array}$ & 45,93 & 58,02 & 76,09 & 70,46 & 75,04 & 62,86 & 70,54 & 72,69 & 66,57 & 63,65 \\
\hline Otros & 0,08 & 0,09 & 0,15 & 8,84 & 7,33 & 1,43 & 1,27 & 0,82 & 6,74 & 7,57 \\
\hline
\end{tabular}

Fuente: Elaboración propia, sobre la base de Comisión Económica para América Latina y el Caribe (CEPAL), base de datos TradeCAN; y O. J. Mandeng, "Análisis de competitividad: Argentina. Estudio de caso basado en el programa computacional CAN", Indicadores Econômicos FEE, vol. 21, № 2, 1993.

a La OCDE es la Organización de Cooperación y Desarrollo Económicos; el MERCOSUR es el Mercado Común del Sur.

En el MERCOSUR se observa un cambio estructural radical que otorga mayor permeabilidad a los productos manufacturados. En ese mercado, la participación de la demanda de recursos naturales y energía se redujo del $50 \%$ al 15\%. En contrapartida, a lo largo del tiempo hubo un aumento de la demanda de manufacturas no basadas en recursos naturales, cuya participación pasó del $46 \%$ al 75\%. El movimiento es simple, claro y constante.

Por otro lado, los cambios ocurridos en la estructura de mercado de los países en desarrollo de Asia son un poco más sutiles y exigen una exposición más detallada. Se observa que, a partir de 2000, se revierte la tendencia hacia la caída de la participación de algunos rubros vinculados a los recursos naturales, en especial las fibras textiles, los minerales y los metales, y las manufacturas basadas en recursos naturales. La energía, por su parte, presenta una desaceleración decreciente.

Este es un punto central en lo que respecta a nuestro análisis, ya que las particularidades citadas son fundamentales para reflexionar acerca de la constatación de Fajnzylber (1991) sobre el mercado de la OCDE (que él analizó) y de los países en desarrollo de Asia (cuya evolución histórica es diferente). De hecho, Fajnzylber constató una tendencia hacia la reducción de la demanda de recursos naturales, energía y manufacturas basadas en recursos naturales por parte de los países de la OCDE en la década de 1980, lo que le pareció preocupante para las economías latinoamericanas, que se basan en la exportación de productos básicos. Los países en desarrollo de Asia son el único mercado 
analizado donde esta tendencia se revierte, aunque sutilmente. Eso es tanto más relevante cuando se considera que dichos países han impulsado la demanda mundial: en 2010, su participación en las importaciones mundiales alcanzó el 28\%. Esto no fue considerado por Fajnzylber y Mandeng.

Hay dos movimientos, quizás menos significativos, que también se distinguen. En los mercados del mundo, la OCDE y el MERCOSUR también se advierte un punto de inflexión en 2000, cuando las fibras textiles, los minerales y los metales, la energía y las manufacturas basadas en recursos naturales dejan de presentar una tendencia definida (aunque no alcancen el peso que tuvieron en 1985). Otra excepción es el grupo de las manufacturas basadas en recursos naturales en el caso del MERCOSUR, que en 2007 presentan mayor peso que al inicio, aunque esa situación no se haya mantenido en 2010.

\section{Estructura comercial argentina}

En la evolución de la estructura comercial argentina se observa que, entre 1985 y 2010, la participación de las manufacturas mejoró hacia todos los destinos, con excepción de los países en desarrollo de Asia (véase el cuadro 4). Dicha mejora fue más tenue entre los productos exportados a la OCDE que entre los exportados al mundo. Aunque en 2007 el valor de las exportaciones de manufacturas no basadas en recursos naturales hacia la OCDE fue más alto que en 2010, dicho valor se mantuvo cercano al 17,5\% desde 1990, mientras que el valor de dichas exportaciones hacia el mundo alcanzó el $31 \%$ del total exportado.

\section{Cuadro 4}

Argentina: estructura de las exportaciones, por destino, 1985-2010 (En porcentajes)

\begin{tabular}{|c|c|c|c|c|c|c|c|c|c|c|}
\hline \multirow{2}{*}{ Sector } & \multicolumn{5}{|c|}{ Mundo } & \multicolumn{5}{|c|}{ OCDE } \\
\hline & 1985 & 1990 & 2000 & 2007 & 2010 & 1985 & 1990 & 2000 & 2007 & 2010 \\
\hline Recursos naturales & 68,83 & 59,41 & 49,10 & 59,49 & 55,94 & 71,64 & 67,41 & 60,76 & 69,55 & 65,52 \\
\hline Agricultura & 65,77 & 55,81 & 46,57 & 56,39 & 53,06 & 68,24 & 63,66 & 57,13 & 64,41 & 60,82 \\
\hline Fibras textiles, minerales y metales & 3,06 & 3,60 & 2,52 & 3,11 & 2,88 & 3,40 & 3,74 & 3,63 & 5,14 & 4,71 \\
\hline Energía & 6,38 & 6,49 & 17,86 & 7,50 & 7,53 & 6,32 & 5,10 & 12,44 & 5,79 & 5,85 \\
\hline Manufacturas & 24,13 & 33,64 & 32,41 & 32,55 & 36,09 & 21,09 & 26,81 & 25,35 & 23,99 & 27,64 \\
\hline $\begin{array}{l}\text { Manufacturas basadas en } \\
\text { recursos naturales }\end{array}$ & 6,99 & 7,25 & 5,01 & 3,79 & 5,07 & 7,72 & 9,12 & 7,90 & 5,54 & 9,78 \\
\hline $\begin{array}{l}\text { Manufacturas no basadas } \\
\text { en recursos naturales }\end{array}$ & 17,15 & 26,38 & 27,40 & 28,77 & 31,01 & 13,37 & 17,69 & 17,45 & 18,45 & 17,86 \\
\hline Otros & 0,50 & 0,47 & 0,63 & 0,45 & 0,44 & 0,51 & 0,56 & 1,45 & 0,66 & 0,99 \\
\hline \multirow{2}{*}{ Sector } & \multicolumn{5}{|c|}{ MERCOSUR } & \multicolumn{5}{|c|}{ Países en desarrollo de Asia } \\
\hline & 1985 & 1990 & 2000 & 2007 & 2010 & 1985 & 1990 & 2000 & 2007 & 2010 \\
\hline Recursos naturales & 54,40 & 49,80 & 31,53 & 28,82 & 25,34 & 74,20 & 49,10 & 79,79 & 85,04 & 85,94 \\
\hline Agricultura & 52,37 & 48,03 & 30,01 & 27,37 & 24,55 & 70,68 & 40,94 & 75,39 & 80,73 & 81,19 \\
\hline Fibras textiles, minerales y metales & 2,03 & 1,77 & 1,52 & 1,46 & 0,79 & 3,52 & 8,17 & 4,39 & 4,31 & 4,75 \\
\hline Energía & 13,68 & 7,50 & 19,03 & 5,03 & 4,35 & 0,00 & 3,19 & 4,91 & 6,20 & 4,54 \\
\hline Manufacturas & 31,88 & 42,44 & 49,44 & 66,14 & 70,30 & 23,87 & 46,56 & 15,18 & 8,74 & 9,36 \\
\hline $\begin{array}{l}\text { Manufacturas basadas en } \\
\text { recursos naturales }\end{array}$ & 9,68 & 4,58 & 2,47 & 2,29 & 1,76 & 6,08 & 6,83 & 6,82 & 3,68 & 4,27 \\
\hline $\begin{array}{l}\text { Manufacturas no basadas } \\
\text { en recursos naturales }\end{array}$ & 22,20 & 37,86 & 46,98 & 63,86 & 68,55 & 17,79 & 39,74 & 8,36 & 5,06 & 5,09 \\
\hline Otros & 0,04 & 0,01 & 0,00 & 0,01 & 0,01 & 1,79 & 0,26 & 0,08 & 0,02 & 0,03 \\
\hline
\end{tabular}

Fuente: Elaboración propia, sobre la base de Comisión Económica para América Latina y el Caribe (CEPAL), base de datos TradeCAN; y O. J. Mandeng, "Análisis de competitividad: Argentina. Estudio de caso basado en el programa computacional CAN", Indicadores Econômicos FEE, vol. 21, № 2, 1993. 
Que el aumento de la participación de las manufacturas haya sido más leve hacia la OCDE que hacia el mundo es un aspecto central, ya que refleja las dificultades que se encuentran cuando se pretende mejorar el patrón de exportaciones de la economía argentina hacia los países industrializados. Sin embargo, el cambio estructural de las exportaciones dirigidas al mundo sugiere que los otros destinos desempeñarían un papel determinante a la hora de modificar la tendencia de la inserción externa argentina. En este sentido, son notables los siguientes cuatro resultados: i) se redujo drásticamente la participación de los productos industrializados con mayor valor agregado en las exportaciones a los países en desarrollo de Asia; ii) se mantuvo la participación de estos productos en las exportaciones a la OCDE; iii) se incrementó levemente su participación en las exportaciones al mundo, y iv) se incrementó en gran medida su participación en las exportaciones al MERCOSUR. Estos resultados, que expresan los casos extremos, merecen ser detallados ya que iluminan el objetivo propuesto.

A pesar de que se verifique una acentuada primarización de las exportaciones dirigidas a los países en desarrollo de Asia, este movimiento, que se inicia en 1990, fue precedido por un período positivo para el patrón de exportaciones argentino, gracias al aumento de la participación de los productos manufacturados en general (que pasó del 24\% al 47\%) y de las manufacturas no basadas en recursos naturales en particular (que aumentaron del 18\% al 40\%). Esto quiere decir que, en 1990, la Argentina exportaba una proporción muy alta de productos manufacturados a los países en desarrollo de Asia. Este patrón de exportaciones en que la participación de las manufacturas representa casi la mitad del comercio es atípico en el país y, desde 2000, solo se observa en las exportaciones destinadas al MERCOSUR.

Durante la década de 1990 se observa que en la Argentina se revierte el camino recorrido en cuanto a las exportaciones industriales a los países en desarrollo de Asia, ya que, en 2000, la participación de las manufacturas en dichas exportaciones es apenas del 15,18\% y, además, la participación de los productos manufacturados más sofisticados - los no basados en recursos naturales - se reduce a una cuarta parte (8,36\%). Esto expresa claramente el debilitamiento del sistema productivo industrial y la restricción efectiva impuesta a las exportaciones de productos manufacturados como resultado de la valorización del tipo de cambio. Estas fueron algunas consecuencias de la implementación simultánea de las políticas neoliberales del consenso de Washington y el Plan de Convertibilidad durante los años noventa en la Argentina ${ }^{11}$.

Por su parte, el MERCOSUR fue muy relevante a la hora de mejorar la estructura de exportaciones de la Argentina. De hecho, en la composición de las exportaciones del país hacia dicho destino se dio un cambio estructural significativo que acompañó la modificación de la estructura de la demanda. Así, en 1985 la participación de las exportaciones de manufacturas era cercana al 32\%, y la de los recursos naturales y la energía, al 68\%. Sin embargo, en 2010 los valores se revierten: las exportaciones de manufacturas pasan a representar el 70\%, y las de recursos naturales y energía, el $30 \%$. Este cambio es aún más notable si se analiza la participación de las manufacturas no basadas en recursos naturales, que se triplicó con creces.

Si se presta atención a los subperíodos, se nota que de 1990 a 2000 la evolución de las exportaciones de manufacturas al MERCOSUR fue más tenue. En este sentido, se podría mencionar que durante el gobierno de Alfonsín (1983-1989) y los gobiernos posteriores a la crisis de 2001, a saber, los de Duhalde (2001-2003), Kirchner (2003-2007) y Fernández (2007-2010), hubo una relación

\footnotetext{
${ }^{11}$ Con el Plan de Convertibilidad se implementó la Ley de Convertibilidad del Austral (Núm. 23.928/1991), en la que se estableció que desde el 1 de abril de 1991 habría una relación cambiaria fija entre la moneda nacional y la estadounidense, a razón de un dólar estadounidense por cada 10.000 australes, lo que posteriormente fue reemplazado por un peso convertible. El objetivo principal de la Ley era estabilizar la economía y eliminar la hiperinflación de los años ochenta. Como resultado, luego de una década de aplicación del plan, el desempleo ascendió al 18,3\% y la población que vivía debajo de la línea de pobreza llegó a representar el 57,6\% del país; cerca de la mitad de dicha población era indigente.
} 
comercial más robusta y asentada en la industria. En sentido opuesto, los gobiernos de Carlos Menem (1989-1999) se asentaron en la liberalización comercial y en la rigidez de un tipo de cambio que tenía un valor elevado, lo que dificultó la producción industrial y aún más la exportación de bienes con mayor valor agregado.

Asimismo, es notable que, al comparar la evolución de las exportaciones hacia el MERCOSUR con la dinámica de los otros mercados, queda claro que el primero fue el más receptivo a los productos industrializados argentinos. Es decir, el MERCOSUR dinamizó la industria nacional argentina al importar productos de valor agregado mediano y alto. Este aspecto es muy importante, porque permite mensurar los resultados que la labor de formación y fortalecimiento del MERCOSUR tuvo en el patrón comercial argentino.

\section{Diez primeros rubros de exportación argentinos}

En los primeros diez rubros de exportación se advierte la gran concentración del patrón comercial argentino. En 2010, estos rubros representaban el 54\% de las exportaciones dirigidas al mundo y el $64 \%$ de las destinadas a la OCDE (véanse los cuadros 5 y 6). Los principales rubros exportados al mundo ya presentaban una concentración bastante inferior a la de los exportados a la OCDE. Es posible vincular el crecimiento de la concentración de la demanda del mundo con la demanda de los países en desarrollo, que serían los responsables de que el comercio mundial se concentre en los principales rubros de exportación.

\section{Cuadro 5}

Argentina: diez primeros rubros exportados al mundo, 1985-2010a

(En porcentajes)

\begin{tabular}{|c|c|c|c|c|c|}
\hline \multirow{2}{*}{ Código de Mandeng } & \multirow{2}{*}{$\begin{array}{l}\text { Código } \\
\text { de rubro }\end{array}$} & \multirow{2}{*}{ Rubros } & \multirow{2}{*}{$\begin{array}{l}\text { Situación según } \\
\text { la matriz de } \\
\text { competitividad }\end{array}$} & \multicolumn{2}{|c|}{ Año } \\
\hline & & & & 1985 & 1990 \\
\hline Agricultura & 81 & Piensos para animales (excepto cereales sin moler) & En retirada & 10,23 & 8,47 \\
\hline Agricultura & 222 & $\begin{array}{l}\text { Semillas y frutas oleaginosas, } \\
\text { enteras o partidas, blandas }\end{array}$ & En retirada & 9,87 & 6,43 \\
\hline Agricultura & 11 & $\begin{array}{l}\text { Carnes y despojos comestibles, frescos, } \\
\text { refrigerados o congelados }\end{array}$ & Situación óptima & 4,72 & 6,02 \\
\hline Agricultura & 423 & Aceites fijos de origen vegetal & Vulnerable & 4,97 & 4,56 \\
\hline Energía & 334 & Productos derivados del petróleo, refinados & Vulnerable & 4,89 & 4,34 \\
\hline $\begin{array}{l}\text { Manufacturas basadas } \\
\text { en recursos naturales }\end{array}$ & 611 & Cuero & Oportunidad perdida & 4,60 & 4,06 \\
\hline Agricultura & 57 & $\begin{array}{l}\text { Frutas y nueces (excepto nueces } \\
\text { oleaginosas), frescas o secas }\end{array}$ & Vulnerable & 2,92 & 3,94 \\
\hline Agricultura & 41 & $\begin{array}{l}\text { Trigo (también escanda) y morcajo } \\
\text { o tranquillón, sin moler }\end{array}$ & En retirada & 5,73 & 3,10 \\
\hline Agricultura & 14 & Preparados, conservas de carne y despojos comestibles & Vulnerable & 2,41 & 3,00 \\
\hline \multirow[t]{2}{*}{ Agricultura } & 34 & Pescado fresco (vivo o muerto), refrigerado o congelado & Situación óptima & 1,33 & 2,68 \\
\hline & & & & 51,68 & 46,60 \\
\hline
\end{tabular}


Cuadro 5 (conclusión)

\begin{tabular}{|c|c|c|c|c|c|}
\hline \multirow{2}{*}{ Código de Mandeng } & \multirow{2}{*}{$\begin{array}{l}\text { Código } \\
\text { de rubro }\end{array}$} & \multirow{2}{*}{ Rubros } & \multirow{2}{*}{$\begin{array}{l}\text { Situación según } \\
\text { la matriz de } \\
\text { competitividad }\end{array}$} & \multicolumn{2}{|c|}{ Año } \\
\hline & & & & 1990 & 2000 \\
\hline Energía & 333 & $\begin{array}{l}\text { Aceites de petróleo crudos, aceites } \\
\text { crudos de minerales bituminosos }\end{array}$ & Vulnerable & 1,33 & 10,22 \\
\hline Agricultura & 81 & Piensos para animales (excepto cereales sin moler) & Vulnerable & 8,47 & 9,26 \\
\hline Agricultura & 222 & $\begin{array}{l}\text { Semillas y frutas oleaginosas, } \\
\text { enteras o partidas, blandas }\end{array}$ & Vulnerable & 6,43 & 5,15 \\
\hline Energía & 334 & Productos derivados del petróleo, refinados & Vulnerable & 4,34 & 4,85 \\
\hline Agricultura & 423 & Aceites fijos de origen vegetal & Vulnerable & 4,56 & 4,76 \\
\hline Agricultura & 41 & $\begin{array}{l}\text { Trigo (también escanda) y morcajo } \\
0 \text { tranquillón, sin moler }\end{array}$ & Vulnerable & 3,10 & 4,59 \\
\hline Agricultura & 44 & Maíz sin moler & Vulnerable & 2,04 & 3,65 \\
\hline $\begin{array}{l}\text { Manufacturas no basadas } \\
\text { en recursos naturales }\end{array}$ & 781 & Automóviles para pasajeros & Situación óptima & 0,25 & 3,15 \\
\hline $\begin{array}{l}\text { Manufacturas basadas } \\
\text { en recursos naturales }\end{array}$ & 611 & Cuero & Vulnerable & 4,06 & 3,09 \\
\hline \multirow[t]{2}{*}{ Agricultura } & 57 & $\begin{array}{l}\text { Frutas y nueces (excepto nueces } \\
\text { oleaginosas), frescas o secas }\end{array}$ & Vulnerable & 3,94 & 2,51 \\
\hline & & & & 38,51 & 51,24 \\
\hline \multirow{2}{*}{ Código de Mandeng } & \multirow{2}{*}{$\begin{array}{l}\text { Código } \\
\text { de rubro }\end{array}$} & \multirow{2}{*}{ Rubros } & \multirow{2}{*}{$\begin{array}{l}\text { Situación según } \\
\text { la matriz de } \\
\text { competitividad }\end{array}$} & \multicolumn{2}{|c|}{ Año } \\
\hline & & & & 2000 & 2007 \\
\hline Agricultura & 81 & Piensos para animales (excepto cereales sin moler) & Vulnerable & 9,30 & 12,51 \\
\hline Agricultura & 222 & $\begin{array}{l}\text { Semillas y frutas oleaginosas, } \\
\text { enteras o partidas, blandas }\end{array}$ & Situación óptima & 6,03 & 8,94 \\
\hline Agricultura & 423 & Aceites fijos de origen vegetal & Situación óptima & 4,38 & 8,93 \\
\hline Agricultura & 44 & Maíz sin moler & Situación óptima & 3,74 & 4,68 \\
\hline $\begin{array}{l}\text { Manufacturas no basadas } \\
\text { en recursos naturales }\end{array}$ & 781 & Automóviles para pasajeros & Vulnerable & 3,11 & 3,93 \\
\hline Energía & 333 & $\begin{array}{l}\text { Aceites de petróleo crudos, aceites } \\
\text { crudos de minerales bituminosos }\end{array}$ & Oportunidad perdida & 10,37 & 3,67 \\
\hline Agricultura & 41 & $\begin{array}{l}\text { Trigo (también escanda) y morcajo } \\
\text { o tranquillón, sin moler }\end{array}$ & Oportunidad perdida & 4,54 & 3,61 \\
\hline Energía & 341 & Gas natural y artificial & Oportunidad perdida & 2,24 & 3,22 \\
\hline $\begin{array}{l}\text { Manufacturas no basadas } \\
\text { en recursos naturales }\end{array}$ & 782 & Vehículos automotores para el transporte de mercancías & Vulnerable & 2,10 & 2,90 \\
\hline \multirow[t]{2}{*}{ Agricultura } & 11 & $\begin{array}{l}\text { Carnes y sobras comestibles, frescas, } \\
\text { refrigeradas o congeladas }\end{array}$ & Vulnerable & 2,17 & 2,60 \\
\hline & & & & 47,98 & 55,00 \\
\hline \multirow{2}{*}{ Código de Mandeng } & \multirow{2}{*}{$\begin{array}{l}\text { Código } \\
\text { de rubro }\end{array}$} & \multirow{2}{*}{ Rubros } & \multirow{2}{*}{$\begin{array}{l}\text { Situación según } \\
\text { la matriz de } \\
\text { competitividad }\end{array}$} & \multicolumn{2}{|c|}{ Año } \\
\hline & & & & 2007 & 2010 \\
\hline Agricultura & 81 & Piensos para animales (excepto cereales sin moler) & Oportunidad perdida & 12,51 & 13,94 \\
\hline Agricultura & 222 & $\begin{array}{l}\text { Semillas y frutas oleaginosas, } \\
\text { enteras o partidas, blandas }\end{array}$ & Oportunidad perdida & 8,94 & 8,12 \\
\hline Agricultura & 423 & Aceites fijos de origen vegetal & En retirada & 8,93 & 6,50 \\
\hline $\begin{array}{l}\text { Manufacturas no basadas } \\
\text { en recursos naturales }\end{array}$ & 781 & Automóviles para pasajeros & Vulnerable & 3,93 & 6,15 \\
\hline Energía & 333 & $\begin{array}{l}\text { Aceites de petróleo crudos, aceites } \\
\text { crudos de minerales bituminosos }\end{array}$ & Vulnerable & 3,67 & 4,81 \\
\hline Agricultura & 44 & Maíz sin moler & En retirada & 4,68 & 3,98 \\
\hline $\begin{array}{l}\text { Manufacturas no basadas } \\
\text { en recursos naturales }\end{array}$ & 782 & Vehículos automotores para el transporte de mercancías & Vulnerable & 2,90 & 3,55 \\
\hline Agricultura & 11 & $\begin{array}{l}\text { Carnes y sobras comestibles, frescas, } \\
\text { refrigeradas o congeladas }\end{array}$ & Situación óptima & 2,60 & 2,84 \\
\hline Agricultura & 57 & $\begin{array}{l}\text { Frutas y nueces (excepto nueces } \\
\text { oleaginosas), frescas o secas }\end{array}$ & Oportunidad perdida & 2,49 & 2,29 \\
\hline $\begin{array}{l}\text { Fibras textiles, } \\
\text { minerales y metales }\end{array}$ & 287 & Minerales de metales comunes y sus concentrados & Vulnerable & 2,54 & 2,26 \\
\hline
\end{tabular}

Fuente: Elaboración propia, sobre la base de Comisión Económica para América Latina y el Caribe (CEPAL), base de datos TradeCAN; y O. J. Mandeng, "Análisis de competitividad: Argentina. Estudio de caso basado en el programa computacional CAN", Indicadores Econômicos FEE, vol. 21, № 2, 1993.

a Los rubros se ordenan según las exportaciones correspondientes al año final. 


\section{Cuadro 6}

Argentina: diez primeros rubros exportados a la Organización de Cooperación y Desarrollo Económicos (OCDE), 1985-2010a

(En porcentajes)

\begin{tabular}{|c|c|c|c|c|c|}
\hline \multirow{2}{*}{ Código de Mandeng } & \multirow{2}{*}{$\begin{array}{l}\text { Código } \\
\text { de rubro }\end{array}$} & \multirow[b]{2}{*}{ Rubros } & \multirow{2}{*}{$\begin{array}{l}\text { Situación según } \\
\text { la matriz de } \\
\text { competitividad }\end{array}$} & \multicolumn{2}{|c|}{ Año } \\
\hline & & & & 1985 & 1990 \\
\hline Agricultura & 81 & Piensos para animales (excepto cereales sin moler) & En retirada & 14,22 & 13,42 \\
\hline Agricultura & 222 & $\begin{array}{l}\text { Semillas y frutas oleaginosas, } \\
\text { enteras o partidas, blandas }\end{array}$ & En retirada & 13,82 & 9,51 \\
\hline Agricultura & 11 & $\begin{array}{l}\text { Carnes y despojos comestibles, frescos, } \\
\text { refrigerados o congelados }\end{array}$ & Situación óptima & 5,98 & 8,72 \\
\hline Agricultura & 57 & $\begin{array}{l}\text { Frutas y nueces (excepto nueces } \\
\text { oleaginosas), frescas o secas }\end{array}$ & Vulnerable & 3,17 & 5,00 \\
\hline Agricultura & 14 & Preparados, conservas de carne y despojos comestibles & Vulnerable & 3,44 & 4,92 \\
\hline $\begin{array}{l}\text { Manufacturas basadas } \\
\text { en recursos naturales }\end{array}$ & 611 & Cuero & Oportunidad perdida & 4,62 & 4,86 \\
\hline Agricultura & 34 & Pescado fresco (vivo o muerto), refrigerado o congelado & Situación óptima & 1,64 & 3,60 \\
\hline Energía & 334 & Productos derivados del petróleo, refinados & Vulnerable & 5,05 & 3,41 \\
\hline $\begin{array}{l}\text { Manufacturas basadas } \\
\text { en recursos naturales }\end{array}$ & 684 & Aluminio & Oportunidad perdida & 2,18 & 2,37 \\
\hline \multirow[t]{2}{*}{ Agricultura } & 58 & Frutas en conserva y preparados de frutas & Situación óptima & 1,30 & 2,20 \\
\hline & & & & 55,41 & 58,02 \\
\hline \multirow{2}{*}{ Código de Mandeng } & \multirow{2}{*}{$\begin{array}{l}\text { Código } \\
\text { de rubro }\end{array}$} & \multirow{2}{*}{ Rubros } & \multirow{2}{*}{$\begin{array}{l}\text { Situación según } \\
\text { la matriz de } \\
\text { competitividad }\end{array}$} & \multicolumn{2}{|c|}{ Año } \\
\hline & & & & 1990 & 2000 \\
\hline Agricultura & 81 & Piensos para animales (excepto cereales sin moler) & Vulnerable & 13,42 & 17,57 \\
\hline Energía & 333 & $\begin{array}{l}\text { Aceites de petróleo crudos, aceites } \\
\text { crudos de minerales bituminosos }\end{array}$ & Vulnerable & 1,17 & 6,70 \\
\hline Agricultura & 57 & $\begin{array}{l}\text { Frutas y nueces (excepto nueces } \\
\text { oleaginosas), frescas o secas }\end{array}$ & Vulnerable & 5,00 & 5,61 \\
\hline Energía & 334 & Productos derivados del petróleo, refinados & Vulnerable & 3,41 & 5,25 \\
\hline Agricultura & 222 & $\begin{array}{l}\text { Semillas y frutas oleaginosas, } \\
\text { enteras o partidas, blandas }\end{array}$ & En retirada & 9,51 & 4,77 \\
\hline $\begin{array}{l}\text { Manufacturas basadas } \\
\text { en recursos naturales }\end{array}$ & 611 & Cuero & Vulnerable & 4,86 & 4,47 \\
\hline Agricultura & 11 & $\begin{array}{l}\text { Carnes y despojos comestibles, frescos, } \\
\text { refrigerados o congelados }\end{array}$ & En retirada & 8,72 & 4,35 \\
\hline Agricultura & 36 & Crustáceos y moluscos pelados o sin pelar & Vulnerable & 1,62 & 4,33 \\
\hline Agricultura & 44 & Maíz sin moler & Vulnerable & 1,74 & 3,50 \\
\hline \multirow[t]{2}{*}{ Agricultura } & 34 & Pescado fresco (vivo o muerto), refrigerado o congelado & En retirada & 3,60 & 3,02 \\
\hline & & & & 53,06 & 59,57 \\
\hline \multirow{2}{*}{ Código de Mandeng } & \multirow{2}{*}{$\begin{array}{l}\text { Código } \\
\text { de rubro }\end{array}$} & \multirow{2}{*}{ Rubros } & \multirow{2}{*}{$\begin{array}{l}\text { Situación según } \\
\text { la matriz de } \\
\text { competitividad }\end{array}$} & \multicolumn{2}{|c|}{ Año } \\
\hline & & & & 2000 & 2007 \\
\hline Agricultura & 81 & Piensos para animales (excepto cereales sin moler) & Vulnerable & 17,57 & 22,86 \\
\hline Agricultura & 57 & $\begin{array}{l}\text { Frutas y nueces (excepto nueces } \\
\text { oleaginosas), frescas o secas }\end{array}$ & Vulnerable & 5,61 & 6,05 \\
\hline Agricultura & 11 & $\begin{array}{l}\text { Carnes y despojos comestibles, frescos, } \\
\text { refrigerados o congelados }\end{array}$ & Vulnerable & 4,35 & 4,99 \\
\hline Energía & 333 & $\begin{array}{l}\text { Aceites de petróleo crudos, aceites } \\
\text { crudos de minerales bituminosos }\end{array}$ & Oportunidad perdida & 6,70 & 4,84 \\
\hline Agricultura & 423 & Aceites fijos de origen vegetal & Situación óptima & 1,42 & 4,54 \\
\hline Agricultura & 44 & Maíz sin moler & Oportunidad perdida & 3,50 & 4,35 \\
\hline $\begin{array}{l}\text { Fibras textiles, } \\
\text { minerales y metales }\end{array}$ & 287 & Minerales de metales comunes y sus concentrados & Oportunidad perdida & 2,55 & 4,32 \\
\hline Agricultura & 36 & Crustáceos y moluscos pelados o sin pelar & Vulnerable & 4,33 & 3,38 \\
\hline Agricultura & 222 & $\begin{array}{l}\text { Semillas y frutas oleaginosas, } \\
\text { enteras o partidas, blandas }\end{array}$ & En retirada & 4,77 & 2,84 \\
\hline \multirow[t]{2}{*}{ Agricultura } & 58 & Frutas en conserva y preparados de frutas & Vulnerable & 2,09 & 2,27 \\
\hline & & & & 52,89 & 60,43 \\
\hline
\end{tabular}


Cuadro 6 (conclusión)

\begin{tabular}{|c|c|c|c|c|c|}
\hline \multirow{2}{*}{ Código de Mandeng } & \multirow{2}{*}{$\begin{array}{l}\text { Código } \\
\text { de rubro }\end{array}$} & \multirow{2}{*}{ Rubros } & \multirow{2}{*}{$\begin{array}{l}\text { Situación según } \\
\text { la matriz de } \\
\text { competitividad }\end{array}$} & \multicolumn{2}{|c|}{ Año } \\
\hline & & & & 2007 & 2010 \\
\hline Agricultura & 81 & Piensos para animales (excepto cereales sin moler) & Oportunidad perdida & 22,86 & 24,44 \\
\hline $\begin{array}{l}\text { Manufacturas no basadas } \\
\text { en recursos naturales }\end{array}$ & 598 & Productos químicos diversos & Situación óptima & 2,10 & 5,55 \\
\hline Energía & 333 & $\begin{array}{l}\text { Aceites de petróleo crudos, aceites } \\
\text { crudos de minerales bituminosos }\end{array}$ & Vulnerable & 4,84 & 5,51 \\
\hline Agricultura & 57 & $\begin{array}{l}\text { Frutas y nueces (excepto nueces } \\
\text { oleaginosas), frescas o secas }\end{array}$ & Oportunidad perdida & 6,05 & 5,28 \\
\hline Agricultura & 11 & $\begin{array}{l}\text { Carnes y despojos comestibles, frescos, } \\
\text { refrigerados o congelados }\end{array}$ & Situación óptima & 4,99 & 5,17 \\
\hline $\begin{array}{l}\text { Fibras textiles, } \\
\text { minerales y metales }\end{array}$ & 287 & Minerales de metales comunes y sus concentrados & Vulnerable & 4,32 & 4,22 \\
\hline $\begin{array}{l}\text { Manufacturas basadas } \\
\text { en recursos naturales }\end{array}$ & 971 & Oro no monetario & Situación óptima & 0,29 & 3,88 \\
\hline Agricultura & 112 & Bebidas alcohólicas & Situación óptima & 2,26 & 3,32 \\
\hline Agricultura & 36 & Crustáceos y moluscos pelados o sin pelar & Situación óptima & 3,38 & 3,23 \\
\hline \multirow[t]{2}{*}{ Agricultura } & 222 & $\begin{array}{l}\text { Semillas y frutas oleaginosas, } \\
\text { enteras o partidas, blandas }\end{array}$ & Oportunidad perdida & 2,84 & 2,95 \\
\hline & & & & 53,94 & 63,56 \\
\hline
\end{tabular}

Fuente: Elaboración propia, sobre la base de Comisión Económica para América Latina y el Caribe (CEPAL), base de datos TradeCAN; y O. J. Mandeng, "Análisis de competitividad: Argentina. Estudio de caso basado en el programa computacional CAN", Indicadores Econômicos FEE, vol. 21, № 2, 1993.

a Los rubros se ordenan según las exportaciones correspondientes al año final.

Es notable que, en todo el período analizado, casi la totalidad de las exportaciones al mundo y a la OCDE hayan sido de recursos naturales y energía. En el período 1985-1990, entre las exportaciones al mundo, los productos agrícolas fueron casi exclusivos, acompañados de la energía (productos refinados derivados del petróleo) y las manufacturas basadas en recursos naturales (cuero). A estos rubros se les sumaron las exportaciones de aluminio hacia la OCDE. Como se ve, son exportaciones de bajo valor agregado.

Los rubros del complejo oleaginoso y cárnico fueron muy importantes en las exportaciones destinadas al mundo y a la OCDE, aunque algo más en el caso de esta última. El complejo oleaginoso es, sin dudas, el sector económico más relevante en las exportaciones argentinas hacia ambos destinos, y su participación viene aumentando. Está integrado por los piensos para animales, las semillas y frutas oleaginosas, y los aceites fijos de origen vegetal. Aunque en 1985 la participación del complejo en las exportaciones al mundo era del 25\%, en 1990 dicha participación cayó al 20\%; solo se advierte un aumento en 2007, cuando alcanzó el 30\%. Una dinámica similar se observa en las exportaciones destinadas a los países industrializados: en 2007, el complejo representaba el 28\% de las exportaciones, valor que ya había tenido en 1985. En 2010 se verifica el impacto que la demanda de los países en desarrollo de Asia tuvo en las exportaciones mundiales. Ese año, por primera vez, la participación del complejo oleaginoso en las exportaciones al mundo supera la participación de dicho complejo en las exportaciones dirigidas a la OCDE.

A partir de 1990 aparece entre los diez primeros rubros exportados al mundo uno que tiene un alto valor agregado: los automóviles para pasajeros. En 2000 se suma otro rubro de la misma cadena productiva, a saber, los vehículos automotores para el transporte de mercancías que, junto con el rubro anterior, en 2010 representa el 10\% de las exportaciones argentinas. Es notable que no haya ocurrido lo mismo con las exportaciones destinadas a la OCDE.

Los productos refinados derivados del petróleo también aparecen entre los primeros diez rubros exportados al mundo y a la OCDE, aunque solo en los dos primeros períodos. La cadena del petróleo, que incluye el grupo de los aceites de petróleo crudos y los aceites crudos de minerales bituminosos, tuvo su ápice en el período 1990-2000, cuando su participación alcanzó el 15\% y el 12\% 
de las exportaciones al mundo y a la OCDE, respectivamente. En los otros períodos, sin embargo, su participación representó aproximadamente una tercera parte de esos valores.

El complejo minero, por su parte, se incorpora a la lista de los primeros diez rubros exportados a la OCDE en el período 2000-2007, y al mundo en el subperíodo siguiente. Se trata del rubro de los minerales de metales comunes y sus concentrados, que en 2010 representó el 2,26\% de las exportaciones al mundo y el $4,22 \%$ de las exportaciones a la OCDE.

En síntesis, se puede decir que el mundo y la OCDE han impulsado la demanda del complejo oleaginoso y, en menor medida, del petróleo y los minerales, actividades esencialmente extractivas. Sin embargo, es solo en el mercado del mundo que la cadena productiva autopartista automotriz se está afianzando desde 1990. Esto es muy importante, ya que se trata de un grupo de actividades cuya consolidación da cuenta de que existe un proceso de aprendizaje, conocimiento e innovación incorporado, que puede difundirse hacia otras cadenas productivas que generan mayor valor agregado en las exportaciones.

Hay también otra constatación digna de nota. Las manufacturas no basadas en recursos naturales aparecen entre los diez primeros productos que la Argentina exportó a la OCDE recién a partir de 2007, con el rubro de los productos químicos diversos. Obsérvese también que, mientras que en la demanda del mundo se dinamiza la cadena automotriz, en la OCDE se mantiene la demanda de productos del complejo cárnico y otros alimentos y, progresivamente, se concede participación al complejo minero. Esto expresa claramente la creciente relevancia que el MERCOSUR y, en particular, el Brasil, tiene para la estructura comercial argentina. El Acuerdo de Complementación Económica № 14 concertado entre la República Argentina y la República Federativa del Brasil en 1990, así como los acuerdos específicos relativos al complejo autopartista automotor, han tenido un impacto directo en la mejora del comercio de la Argentina.

En los primeros diez rubros de exportación de la Argentina al MERCOSUR también se observa la gran concentración del patrón comercial (véase el cuadro 7). La concentración era menor en 1990, cuando estos rubros representaron el 46\% de las exportaciones; sin embargo, en 2010, representaron el 59\%. Además, hubo un cambio radical en cuanto a los productos preponderantes, que dejaron de ser los recursos naturales y pasaron a ser las manufacturas no basadas en recursos naturales.

Cuadro 7

Argentina: diez primeros rubros exportados al Mercado Común del Sur (MERCOSUR), 1985-2010ª (En porcentajes)

\begin{tabular}{|c|c|c|c|c|c|}
\hline \multirow{2}{*}{ Código de Mandeng } & \multirow{2}{*}{$\begin{array}{l}\text { Código } \\
\text { de rubro }\end{array}$} & \multirow{2}{*}{ Rubros } & \multirow{2}{*}{$\begin{array}{l}\text { Situación según } \\
\text { la matriz de } \\
\text { competitividad }\end{array}$} & \multicolumn{2}{|c|}{ Año } \\
\hline & & & & 1985 & 1990 \\
\hline Agricultura & 41 & $\begin{array}{l}\text { Trigo (también escanda) y morcajo } \\
\text { o tranquillón, sin moler }\end{array}$ & Vulnerable & 16,34 & 8,77 \\
\hline Agricultura & 48 & Preparados de cereales y de harina fina & Situación óptima & 0,55 & 7,09 \\
\hline Agricultura & 57 & $\begin{array}{l}\text { Frutas y nueces (excepto nueces } \\
\text { oleaginosas), frescas o secas }\end{array}$ & Situación óptima & 5,89 & 5,65 \\
\hline Agricultura & 54 & $\begin{array}{l}\text { Legumbres frescas, refrigeradas, } \\
\text { congeladas, conservadas }\end{array}$ & Situación óptima & 4,20 & 5,09 \\
\hline Energía & 334 & Productos derivados del petróleo, refinados & Oportunidad perdida & 10,70 & 4,76 \\
\hline $\begin{array}{l}\text { Manufacturas basadas } \\
\text { en recursos naturales }\end{array}$ & 611 & Cuero & Oportunidad perdida & 8,74 & 3,56 \\
\hline $\begin{array}{l}\text { Manufacturas no basadas } \\
\text { en recursos naturales }\end{array}$ & 784 & Partes y accesorios de vehículos automotores & Vulnerable & 3,74 & 3,15 \\
\hline Agricultura & 44 & Maíz sin moler & Vulnerable & 4,91 & 3,00 \\
\hline Agricultura & 11 & $\begin{array}{l}\text { Carnes y despojos comestibles, frescos, } \\
\text { refrigerados o congelados }\end{array}$ & Vulnerable & 1,93 & 2,48 \\
\hline \multirow[t]{2}{*}{ Agricultura } & 34 & Pescado fresco (vivo o muerto), refrigerado o congelado & Vulnerable & 1,26 & 2,43 \\
\hline & & & & 58,25 & 46,00 \\
\hline
\end{tabular}


Cuadro 7 (continuación)

\begin{tabular}{|c|c|c|c|c|c|}
\hline \multirow{2}{*}{ Código de Mandeng } & \multirow{2}{*}{$\begin{array}{l}\text { Código } \\
\text { de rubro }\end{array}$} & \multirow{2}{*}{ Rubros } & \multirow{2}{*}{$\begin{array}{l}\text { Situación según } \\
\text { la matriz de } \\
\text { competitividad }\end{array}$} & \multicolumn{2}{|c|}{ Año } \\
\hline & & & & 1990 & 2000 \\
\hline Agricultura & 41 & $\begin{array}{l}\text { Trigo (también escanda) y morcajo } \\
\text { o tranquillón, sin moler }\end{array}$ & Situación óptima & 8,77 & 11,95 \\
\hline Energía & 333 & $\begin{array}{l}\text { Aceites de petróleo crudos, aceites } \\
\text { crudos de minerales bituminosos }\end{array}$ & Vulnerable & 1,03 & 8,97 \\
\hline $\begin{array}{l}\text { Manufacturas no basadas } \\
\text { en recursos naturales }\end{array}$ & 781 & Automóviles para pasajeros & Situación óptima & 1,12 & 8,85 \\
\hline Energía & 334 & Productos derivados del petróleo, refinados & Situación óptima & 4,76 & 6,65 \\
\hline $\begin{array}{l}\text { Manufacturas no basadas } \\
\text { en recursos naturales }\end{array}$ & 782 & Vehículos automotores para el transporte de mercancías & Situación óptima & 0,26 & 5,65 \\
\hline $\begin{array}{l}\text { Manufacturas no basadas } \\
\text { en recursos naturales }\end{array}$ & 784 & Partes y accesorios de vehículos automotores & Oportunidad perdida & 3,15 & 3,09 \\
\hline Energía & 341 & Gas natural y artificial & Vulnerable & 0,86 & 2,98 \\
\hline Agricultura & 22 & Leche y crema & Vulnerable & 1,93 & 2,45 \\
\hline Agricultura & 54 & $\begin{array}{l}\text { Legumbres frescas, refrigeradas, } \\
\text { congeladas, conservadas }\end{array}$ & Vulnerable & 5,09 & 2,33 \\
\hline \multirow[t]{2}{*}{$\begin{array}{l}\text { Manufacturas no basadas } \\
\text { en recursos naturales }\end{array}$} & 583 & Productos de polimerización y copolimerización & Oportunidad perdida & 2,19 & 2,10 \\
\hline & & & & 29,16 & 55,02 \\
\hline \multirow{2}{*}{ Código de Mandeng } & \multirow{2}{*}{$\begin{array}{l}\text { Código } \\
\text { de rubro }\end{array}$} & \multirow{2}{*}{ Rubros } & \multirow{2}{*}{$\begin{array}{l}\text { Situación según } \\
\text { la matriz de } \\
\text { competitividad }\end{array}$} & \multicolumn{2}{|c|}{ Año } \\
\hline & & & & 2000 & 2007 \\
\hline $\begin{array}{l}\text { Manufacturas no basadas } \\
\text { en recursos naturales }\end{array}$ & 781 & Automóviles para pasajeros & Oportunidad perdida & 8,85 & 14,78 \\
\hline Agricultura & 41 & $\begin{array}{l}\text { Trigo (también escanda) y morcajo } \\
\text { o tranquillón, sin moler }\end{array}$ & En retirada & 11,95 & 9,93 \\
\hline $\begin{array}{l}\text { Manufacturas no basadas } \\
\text { en recursos naturales }\end{array}$ & 782 & Vehículos automotores para el transporte de mercancías & En retirada & 5,65 & 6,73 \\
\hline $\begin{array}{l}\text { Manufacturas no basadas } \\
\text { en recursos naturales }\end{array}$ & 784 & Partes y accesorios de vehículos automotores & Situación óptima & 3,09 & 5,33 \\
\hline $\begin{array}{l}\text { Manufacturas no basadas } \\
\text { en recursos naturales }\end{array}$ & 583 & Productos de polimerización y copolimerización & Vulnerable & 2,10 & 4,70 \\
\hline Energía & 341 & Gas natural y artificial & Oportunidad perdida & 2,98 & 3,84 \\
\hline $\begin{array}{l}\text { Manufacturas no basadas } \\
\text { en recursos naturales }\end{array}$ & 591 & Desinfectantes, insecticidas, fungicidas, herbicidas & Situación óptima & 0,88 & 2,44 \\
\hline Agricultura & 54 & $\begin{array}{l}\text { Legumbres frescas, refrigeradas, } \\
\text { congeladas, conservadas }\end{array}$ & Vulnerable & 2,33 & 2,18 \\
\hline Agricultura & 48 & Preparados de cereales y de harina fina & Vulnerable & 1,29 & 1,85 \\
\hline \multirow[t]{2}{*}{ Agricultura } & 57 & $\begin{array}{l}\text { Frutas y nueces (excepto nueces } \\
\text { oleaginosas), frescas o secas }\end{array}$ & Vulnerable & 1,16 & 1,57 \\
\hline & & & & 40,28 & 53,35 \\
\hline \multirow{2}{*}{ Código de Mandeng } & \multirow{2}{*}{$\begin{array}{l}\text { Código } \\
\text { de rubro }\end{array}$} & \multirow[b]{2}{*}{ Rubros } & \multirow{2}{*}{$\begin{array}{l}\text { Situación según } \\
\text { la matriz de } \\
\text { competitividad }\end{array}$} & \multicolumn{2}{|c|}{ Año } \\
\hline & & & & 2007 & 2010 \\
\hline $\begin{array}{l}\text { Manufacturas no basadas } \\
\text { en recursos naturales }\end{array}$ & 781 & Automóviles para pasajeros & Situación óptima & 14,78 & 23,52 \\
\hline $\begin{array}{l}\text { Manufacturas no basadas } \\
\text { en recursos naturales }\end{array}$ & 782 & Vehículos automotores para el transporte de mercancías & Situación óptima & 6,73 & 9,95 \\
\hline Agricultura & 41 & $\begin{array}{l}\text { Trigo (también escanda) y morcajo } \\
\text { o tranquillón, sin moler }\end{array}$ & En retirada & 9,93 & 5,92 \\
\hline $\begin{array}{l}\text { Manufacturas no basadas } \\
\text { en recursos naturales }\end{array}$ & 784 & Partes y accesorios de vehículos automotores & Situación óptima & 5,33 & 5,38 \\
\hline $\begin{array}{l}\text { Manufacturas no basadas } \\
\text { en recursos naturales }\end{array}$ & 583 & Productos de polimerización y copolimerización & Oportunidad perdida & 4,70 & 3,73 \\
\hline Energía & 341 & Gas natural y artificial & Oportunidad perdida & 3,84 & 2,41 \\
\hline Agricultura & 54 & $\begin{array}{l}\text { Legumbres frescas, refrigeradas, } \\
\text { congeladas, conservadas }\end{array}$ & Oportunidad perdida & 2,18 & 2,40 \\
\hline Agricultura & 48 & Preparados de cereales y de harina fina & Situación óptima & 1,85 & 2,24 \\
\hline
\end{tabular}


Cuadro 7 (conclusión)

\begin{tabular}{|c|c|c|c|c|c|}
\hline \multirow{2}{*}{ Código de Mandeng } & \multirow{2}{*}{$\begin{array}{l}\text { Código } \\
\text { de rubro }\end{array}$} & \multirow{2}{*}{ Rubros } & \multirow{2}{*}{$\begin{array}{l}\text { Situación según } \\
\text { la matriz de } \\
\text { competitividad }\end{array}$} & \multicolumn{2}{|c|}{ Año } \\
\hline & & & & 2007 & 2010 \\
\hline $\begin{array}{l}\text { Manufacturas no basadas } \\
\text { en recursos naturales }\end{array}$ & 591 & Desinfectantes, insecticidas, fungicidas, herbicidas & Oportunidad perdida & 2,44 & 1,85 \\
\hline Agricultura & 57 & $\begin{array}{l}\text { Frutas y nueces (excepto nueces } \\
\text { oleaginosas), frescas o secas }\end{array}$ & Oportunidad perdida & 1,57 & 1,70 \\
\hline & & & & 53,35 & 59,11 \\
\hline
\end{tabular}

Fuente: Elaboración propia, sobre la base de Comisión Económica para América Latina y el Caribe (CEPAL), base de datos TradeCAN; y O. J. Mandeng, "Análisis de competitividad: Argentina. Estudio de caso basado en el programa computacional CAN", Indicadores Econômicos FEE, vol. 21, № 2, 1993.

a Los rubros se ordenan según las exportaciones correspondientes al año final.

En el período 1985-1990, las exportaciones de productos agrícolas fueron casi exclusivas y estuvieron acompañadas de la exportación de energía (productos derivados del petróleo, refinados). Ya en este período aparece la exportación de manufacturas no basadas en recursos naturales, a través del rubro de las partes y accesorios de vehículos automotores.

En este período se destacan, entre los recursos naturales, el complejo cerealero, el de frutas y legumbres, y el cárnico, aunque van perdiendo relevancia. La participación del complejo cerealero se redujo del 19\% al 8\%. La del complejo de frutas y legumbres pasó del $11 \%$ al 4\%, y la del complejo cárnico, que al principio representaba un 5\% de las exportaciones, dejó de figurar entre los diez primeros.

Entre las manufacturas no basadas en recursos naturales, se destaca el complejo autopartista y automotor, que pasó del 3\% en 1990 al 17\% en 2000. En 2007, la participación de este complejo era del 27\% y, en 2010, del 39\%. Este es, sin dudas, el principal cambio verificado.

La industria química, por su parte, cobró relevancia desde 1990 con los productos de la polimerización, a los que desde 2000 se les sumaron los desinfectantes, insecticidas, fungicidas y herbicidas. El primer rubro está vinculado al complejo automotor y, el último, al complejo oleaginoso.

Se puede concluir que los diez primeros rubros exportados al MERCOSUR dejaron de ser mayoritariamente recursos naturales y pasaron a ser manufacturas no basadas en recursos naturales, en especial las que pertenecen a los rubros que integran el complejo autopartista y automotor. Otro elemento para destacar es que las manufacturas basadas en recursos naturales solo aparecen entre los diez primeros en el primer subperíodo, con el rubro del cuero.

En las exportaciones destinadas al mercado de los países en desarrollo de Asia la concentración es aún más radical (véase el cuadro 8). De hecho, los diez primeros rubros definen de manera casi exclusiva el total de las exportaciones, ya que, en 2010, representaban el 91\% de ellas. Este nivel de concentración no se advierte en ningún otro destino. 


\section{Cuadro 8}

Argentina: diez primeros rubros exportados a los países en desarrollo de Asia, 1985-2010ª (En porcentajes)

\begin{tabular}{|c|c|c|c|c|c|}
\hline \multirow{2}{*}{ Código de Mandeng } & \multirow{2}{*}{$\begin{array}{l}\text { Código } \\
\text { de rubro }\end{array}$} & \multirow{2}{*}{ Rubros } & \multirow{2}{*}{$\begin{array}{l}\text { Situación según } \\
\text { la matriz de } \\
\text { competitividad }\end{array}$} & \multicolumn{2}{|c|}{ Año } \\
\hline & & & & 1985 & 1990 \\
\hline Agricultura & 423 & Aceites fijos de origen vegetal & Vulnerable & 12,20 & 15,33 \\
\hline $\begin{array}{l}\text { Manufacturas no basadas } \\
\text { en recursos naturales }\end{array}$ & 678 & Tubos y accesorios de tubería de hierro o acero & Vulnerable & 2,34 & 12,82 \\
\hline Agricultura & 41 & $\begin{array}{l}\text { Trigo (también escanda) y morcajo } \\
\text { o tranquillón, sin moler }\end{array}$ & En retirada & 26,55 & 8,57 \\
\hline $\begin{array}{l}\text { Manufacturas no basadas } \\
\text { en recursos naturales }\end{array}$ & 672 & Lingotes y otras formas primarias de hierro o acero & Situación óptima & 3,21 & 6,43 \\
\hline $\begin{array}{l}\text { Manufacturas no basadas } \\
\text { en recursos naturales }\end{array}$ & 674 & Planos universales, chapas y planchas de hierro o acero & Situación óptima & 0,00 & 5,69 \\
\hline $\begin{array}{l}\text { Manufacturas basadas } \\
\text { en recursos naturales }\end{array}$ & 611 & Cuero & Situación óptima & 4,23 & 5,24 \\
\hline $\begin{array}{l}\text { Fibras textiles, } \\
\text { minerales y metales }\end{array}$ & 263 & Algodón & Situación óptima & 1,58 & 4,92 \\
\hline Agricultura & 11 & $\begin{array}{l}\text { Carnes y despojos comestibles, frescos, } \\
\text { refrigerados o congelados }\end{array}$ & Vulnerable & 2,52 & 3,26 \\
\hline Energía & 334 & Productos derivados del petróleo, refinados & Vulnerable & 0,00 & 2,97 \\
\hline \multirow[t]{2}{*}{$\begin{array}{l}\text { Manufacturas no basadas } \\
\text { en recursos naturales }\end{array}$} & 583 & Productos de polimerización y copolimerización & Situación óptima & 0,37 & 2,67 \\
\hline & & & & 52,99 & 67,90 \\
\hline \multirow{2}{*}{ Código de Mandeng } & \multirow{2}{*}{$\begin{array}{l}\text { Código } \\
\text { de rubro }\end{array}$} & \multirow{2}{*}{ Rubros } & \multirow{2}{*}{$\begin{array}{l}\text { Situación según } \\
\text { la matriz de } \\
\text { competitividad }\end{array}$} & \multicolumn{2}{|c|}{ Año } \\
\hline & & & & 1990 & 2000 \\
\hline Agricultura & 222 & $\begin{array}{l}\text { Semillas y frutas oleaginosas, } \\
\text { enteras o partidas, blandas }\end{array}$ & Situación óptima & 2,55 & 32,55 \\
\hline Agricultura & 423 & Aceites fijos de origen vegetal & Vulnerable & 15,33 & 16,40 \\
\hline Agricultura & 81 & Piensos para animales (excepto cereales sin moler) & Vulnerable & 1,72 & 14,04 \\
\hline Agricultura & 44 & Maíz sin moler & Vulnerable & 2,05 & 6,59 \\
\hline $\begin{array}{l}\text { Manufacturas basadas } \\
\text { en recursos naturales }\end{array}$ & 611 & Cuero & Situación óptima & 5,24 & 6,59 \\
\hline $\begin{array}{l}\text { Fibras textiles, } \\
\text { minerales y metales }\end{array}$ & 287 & Minerales de metales comunes y sus concentrados & Vulnerable & 0,34 & 3,25 \\
\hline $\begin{array}{l}\text { Manufacturas no basadas } \\
\text { en recursos naturales }\end{array}$ & 678 & Tubos y accesorios de tubería de hierro o acero & En retirada & 12,82 & 2,55 \\
\hline Agricultura & 11 & $\begin{array}{l}\text { Carnes y despojos comestibles, frescos, } \\
\text { refrigerados o congelados }\end{array}$ & Oportunidad perdida & 3,26 & 1,32 \\
\hline $\begin{array}{l}\text { Manufacturas no basadas } \\
\text { en recursos naturales }\end{array}$ & 651 & Hilos de fibras textiles & En retirada & 2,39 & 1,17 \\
\hline \multirow[t]{2}{*}{ Agricultura } & 41 & $\begin{array}{l}\text { Trigo (también escanda) y morcajo } \\
\text { o tranquillón, sin moler }\end{array}$ & En retirada & 8,57 & 1,04 \\
\hline & & & & 54,26 & 85,51 \\
\hline \multirow{2}{*}{ Código de Mandeng } & \multirow{2}{*}{$\begin{array}{l}\text { Código } \\
\text { de rubro }\end{array}$} & \multirow{2}{*}{ Rubros } & \multirow{2}{*}{$\begin{array}{l}\text { Situación según } \\
\text { la matriz de } \\
\text { competitividad }\end{array}$} & \multicolumn{2}{|c|}{ Año } \\
\hline & & & & 2000 & 2007 \\
\hline Agricultura & 222 & $\begin{array}{l}\text { Semillas y frutas oleaginosas, } \\
\text { enteras o partidas, blandas }\end{array}$ & Situación óptima & 32,55 & 34,63 \\
\hline Agricultura & 423 & Aceites fijos de origen vegetal & Situación óptima & 16,40 & 22,18 \\
\hline Agricultura & 81 & Piensos para animales (excepto cereales sin moler) & Vulnerable & 14,04 & 13,61 \\
\hline Energía & 333 & $\begin{array}{l}\text { Aceites de petróleo crudos, aceites } \\
\text { crudos de minerales bituminosos }\end{array}$ & Situación óptima & 4,77 & 5,78 \\
\hline $\begin{array}{l}\text { Fibras textiles, } \\
\text { minerales y metales }\end{array}$ & 287 & Minerales de metales comunes y sus concentrados & Oportunidad perdida & 3,25 & 3,89 \\
\hline $\begin{array}{l}\text { Manufacturas basadas } \\
\text { en recursos naturales }\end{array}$ & 611 & Cuero & Vulnerable & 6,59 & 3,46 \\
\hline Agricultura & 44 & Maíz sin moler & En retirada & 6,59 & 3,42 \\
\hline Agricultura & 41 & $\begin{array}{l}\text { Trigo (también escanda) y morcajo } \\
\text { o tranquillón, sin moler }\end{array}$ & Vulnerable & 1,04 & 2,22 \\
\hline
\end{tabular}


Cuadro 8 (conclusión)

\begin{tabular}{|c|c|c|c|c|c|}
\hline \multirow{2}{*}{ Código de Mandeng } & \multirow{2}{*}{$\begin{array}{l}\text { Código } \\
\text { de rubro }\end{array}$} & \multirow{2}{*}{ Rubros } & \multirow{2}{*}{$\begin{array}{l}\text { Situación según } \\
\text { la matriz de } \\
\text { competitividad }\end{array}$} & \multicolumn{2}{|c|}{ Año } \\
\hline & & & & 2000 & 2007 \\
\hline Agricultura & 11 & $\begin{array}{l}\text { Carnes y despojos comestibles, frescos, } \\
\text { refrigerados o congelados }\end{array}$ & Vulnerable & 1,32 & 1,91 \\
\hline \multirow[t]{2}{*}{$\begin{array}{l}\text { Manufacturas no basadas } \\
\text { en recursos naturales }\end{array}$} & 678 & Tubos y accesorios de tubería de hierro o acero & Oportunidad perdida & 2,55 & 0,74 \\
\hline & & & & 89,11 & 91,84 \\
\hline \multirow{2}{*}{ Código de Mandeng } & \multirow{2}{*}{$\begin{array}{l}\text { Código } \\
\text { de rubro }\end{array}$} & \multirow{2}{*}{ Rubros } & \multirow{2}{*}{$\begin{array}{l}\text { Situación según } \\
\text { la matriz de } \\
\text { competitividad }\end{array}$} & \multicolumn{2}{|c|}{ Año } \\
\hline & & & & 2007 & 2010 \\
\hline Agricultura & 222 & $\begin{array}{l}\text { Semillas y frutas oleaginosas, } \\
\text { enteras o partidas, blandas }\end{array}$ & Oportunidad perdida & 34,63 & 33,13 \\
\hline Agricultura & 423 & Aceites fijos de origen vegetal & Oportunidad perdida & 22,18 & 19,25 \\
\hline Agricultura & 81 & Piensos para animales (excepto cereales sin moler) & Oportunidad perdida & 13,61 & 17,72 \\
\hline Energía & 333 & $\begin{array}{l}\text { Aceites de petróleo crudos, aceites } \\
\text { crudos de minerales bituminosos }\end{array}$ & En retirada & 5,78 & 4,39 \\
\hline Agricultura & 44 & Maíz sin moler & Vulnerable & 3,42 & 4,25 \\
\hline $\begin{array}{l}\text { Manufacturas basadas } \\
\text { en recursos naturales }\end{array}$ & 611 & Cuero & Vulnerable & 3,46 & 3,95 \\
\hline $\begin{array}{l}\text { Fibras textiles, } \\
\text { minerales y metales }\end{array}$ & 287 & Minerales de metales comunes y sus concentrados & En retirada & 3,89 & 3,87 \\
\hline Agricultura & 11 & $\begin{array}{l}\text { Carnes y despojos comestibles, frescos, } \\
\text { refrigerados o congelados }\end{array}$ & Situación óptima & 1,91 & 2,84 \\
\hline Agricultura & 121 & Tabaco bruto y residuos de tabaco & Situación óptima & 0,39 & 0,83 \\
\hline \multirow[t]{2}{*}{$\begin{array}{l}\text { Manufacturas no basadas } \\
\text { en recursos naturales }\end{array}$} & 541 & Productos medicinales y farmacéuticos & Oportunidad perdida & 0,41 & 0,58 \\
\hline & & & & 89,69 & 90,81 \\
\hline
\end{tabular}

Fuente: Elaboración propia, sobre la base de Comisión Económica para América Latina y el Caribe (CEPAL), base de datos TradeCAN; y O. J. Mandeng, "Análisis de competitividad: Argentina. Estudio de caso basado en el programa computacional CAN", Indicadores Econômicos FEE, vol. 21, № 2, 1993.

a Los rubros se ordenan según las exportaciones correspondientes al año final.

Los primeros diez rubros se modificaron de forma sustancial durante el período analizado. Al inicio, los rubros de las manufacturas no basadas en recursos naturales eran los más relevantes y representaban casi el $28 \%$ de las exportaciones, seguidos por los de la agricultura, que representaban aproximadamente el $27 \%$. Sin embargo, en la década siguiente, los rubros de la agricultura llegaron a representar casi tres cuartas partes de las exportaciones, y los de las manufacturas no basadas en recursos naturales, solo el 3,72\%. En los subperíodos siguientes, la relación entre la agricultura y las manufacturas no basadas en recursos naturales se mantuvo, si bien la diferencia aumentó, ya que llegaron a representar el $78 \%$ y el 1\% de las exportaciones, respectivamente.

En este sentido, también se observa que de 1985 a 1990 los diez primeros rubros estaban más diversificados que en los otros períodos. A modo de ejemplo, hasta 1990 había tres complejos productivos que se destacaban: el siderúrgico (manufacturas no basadas en recursos naturales), el oleaginoso (agricultura), y la carne y el cuero (agricultura y manufacturas basadas en recursos naturales). No obstante, de 1990 a 2000 la participación del complejo oleaginoso aumentó y dejó poco margen para otros rubros. De hecho, este complejo absorbió el 63\% de las exportaciones en 2007 y el 70\% en 2010, sin indicios de reversión.

Aunque en la estructura de las exportaciones de los diez primeros rubros hacia los países en desarrollo de Asia existen dos momentos bien marcados, cuyo punto de inflexión es 1990, se advierten algunas particularidades en la composición de los rubros de las fibras textiles, los minerales y los metales, la energía y las manufacturas basadas en recursos naturales. Así, en el caso del primer rubro, las exportaciones eran de algodón - que es un insumo para la industria textil - y pasaron a ser de minerales de metales comunes y sus concentrados - que son un insumo para la industria de la 
construcción, principalmente-. Las exportaciones de energía eran de productos refinados derivados del petróleo, y pasaron a ser de aceites de petróleo crudos y aceites crudos de minerales bituminosos. La industria del cuero es el único rubro de las manufacturas basadas en recursos naturales que está presente dentro de los diez primeros durante todos los años analizados.

Por su parte, entre los rubros manufacturados más sofisticados, vemos que hasta 1990 se destaca el complejo siderúrgico, representado por el grupo de los tubos y accesorios de tubería de hierro y acero, acompañado por un rubro que aporta al complejo autopartista automotor: los productos de la polimerización y la copolimerización. En los años noventa, el primer grupo siguió estando presente, pero tuvo una caída acentuada de 1990 a 2000, cuando llegó a representar menos de un cuarto de lo que representaba en el período anterior y dejó de figurar en el último período.

Cabe destacar que la producción y la exportación de tubos de hierro y acero están en manos de una de las principales empresas argentinas con dimensión internacional, el grupo económico Techint ${ }^{12}$. En 1990, las exportaciones de tubos de hierro y acero constituían casi el $13 \%$ de las exportaciones nacionales. La abrupta caída de la participación de este rubro es muy importante para nuestro análisis, ya que expresa la oportunidad perdida por la Argentina de mantener una posición estratégica en el mercado asiático. Por otro lado, el hecho de que a partir de 2007 aparezca el rubro de los productos medicinales y farmacéuticos entre los diez primeros muestra el ascenso de la industria química más sofisticada.

Al comparar con las exportaciones a otros destinos, vemos que en los países en desarrollo de Asia el complejo de las oleaginosas tuvo un crecimiento vertiginoso de 1990 a 2000, que no se observó en los otros destinos y que se mantuvo hasta el último año analizado: en 2010, representaba el $70 \%$ de las exportaciones a los países en desarrollo de Asia, y alrededor del $28 \%$ al mundo y a la OCDE. Es notable que este complejo ni siquiera figure entre los diez primeros productos exportados al MERCOSUR. Finalmente, mientras que los rubros de las manufacturas no basadas en recursos naturales aparecen entre los diez primeros productos exportados a la OCDE recién en 2007, hasta 1990 eran mucho más relevantes en la composición de las exportaciones destinadas a los países en desarrollo de Asia.

\section{Matriz de competitividad argentina}

En la matriz de competitividad argentina, como vimos, se relaciona la evolución del patrón comercial del país con la evolución de los mercados, lo que nos permite visualizar, por medio de radiales y en relación con cada subperíodo de análisis, cómo se componen las exportaciones en términos de la clasificación cuaternaria, a saber: situación óptima, situación de vulnerabilidad, situación de oportunidades perdidas y situación de retirada (véase el gráfico 2). Los principales resultados se exponen a continuación.

En las exportaciones hacia el mundo, el hecho de que los valores mayores correspondan a los grupos vulnerables y en retirada muestra que en el perfil de exportaciones de la Argentina predominan grupos cuya demanda está decreciendo, esto es, una gran proporción de las exportaciones (el 59\%, el $82 \%$, el $50 \%$ y el $45 \%$ de cada período, respectivamente) corresponde a grupos poco dinámicos. Entre los períodos analizados, el peor es el de 1990-2000, cuando casi el 70\% de las exportaciones del país se concentraba en grupos vulnerables.

\footnotetext{
12 Véase un análisis histórico sobre la constitución de la empresa multinacional Techint, su organización empresarial y su internacionalización temprana en Castro (2011).
} 


\section{Gráfico 2}

Argentina: matriz de competitividad, por destino, 1985-2010

(En porcentajes) $)^{a}$

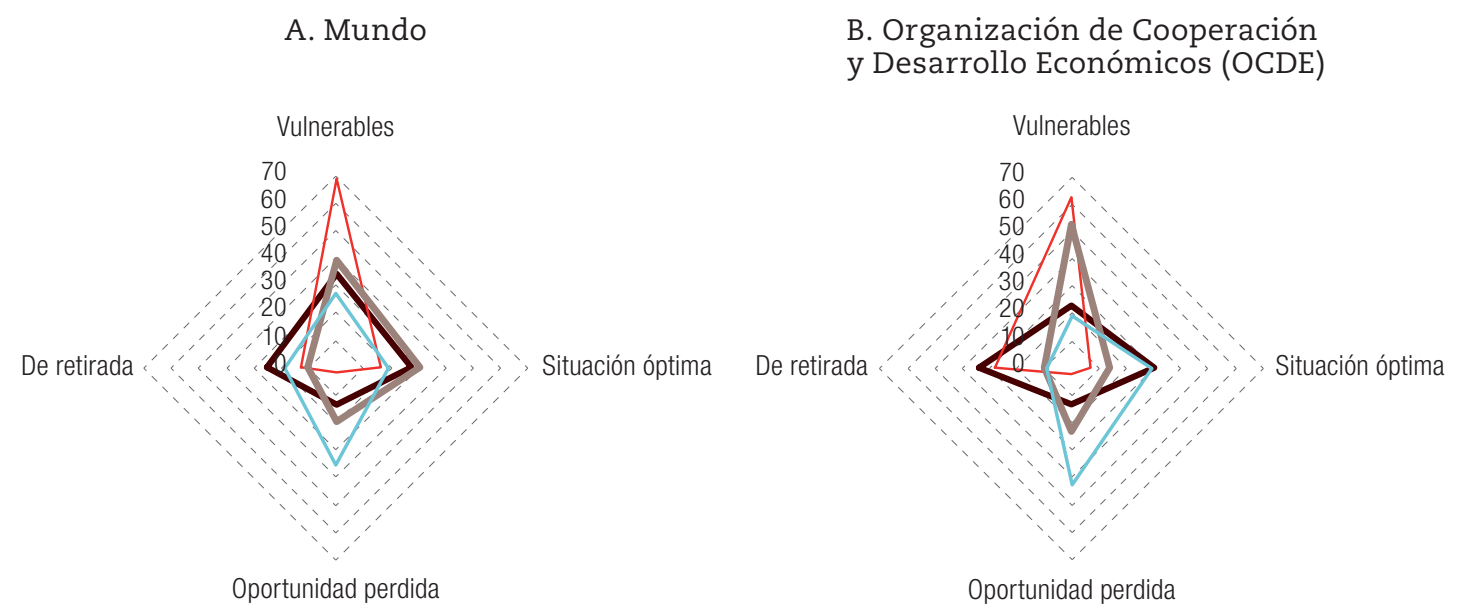

C. Mercado Común del Sur (MERCOSUR)

D. Países en desarrollo de Asia
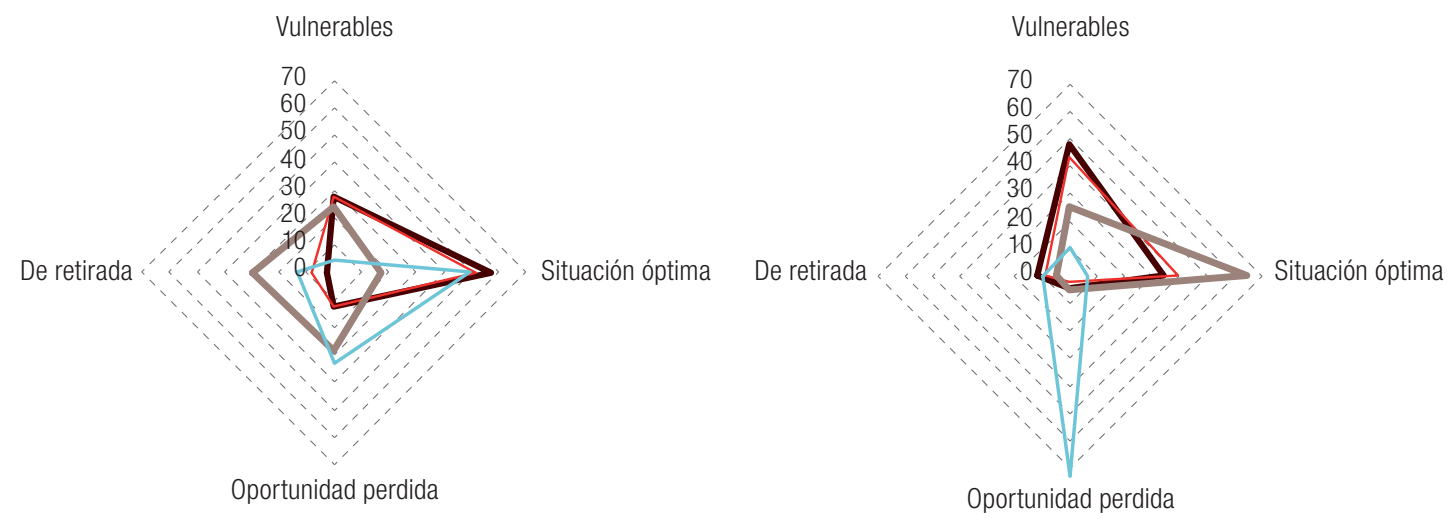

-1985-1990 - 1990-2000 2000-2007 - 2007-2010

Fuente: Elaboración propia, sobre la base de Comisión Económica para América Latina y el Caribe (CEPAL), base de datos TradeCAN.

a Los porcentajes corresponden a las exportaciones en el año final.

Asimismo, se verifica una mejora del período 1990-2000 al 2000-2007, cuando aumentó la participación de las exportaciones en situación óptima y se redujo la participación de las que estaban en situación de vulnerabilidad y en retirada. Sin embargo, el aumento de las exportaciones en situación de oportunidades perdidas muestra que el país podría haber ganado espacio en algunos mercados que se estaban dinamizando, pero no lo hizo. Este proceso es aún más evidente en el período 2007-2010, ya que las exportaciones en esa situación ascendieron a más de un tercio del total exportado. A pesar de ello, este es el único período en que las exportaciones dinámicas superaron a las que no lo eran.

En las exportaciones a la OCDE se visualiza una pésima situación, ya que las exportaciones se concentraron en sectores cuya demanda estaba decreciendo, esto es, en grupos vulnerables y en retirada (el 56\%, el 90\%, el 63\% y el $28 \%$ de cada período, respectivamente). Y si bien en el 
período 1985-1990 las exportaciones dinámicas ganaron un espacio significativo y su participación llegó al 43\%, dichas exportaciones se hicieron más relevantes en el período 2007-2010, cuando concentraron casi tres cuartas partes del total.

Las exportaciones de grupos vulnerables a la OCDE fueron muy elevadas en 1990 (63\%) y en 2000, cuando representaron más del 50\% del total. Esa caracterización se vincula directamente con la estructura de las exportaciones hacia ese mercado: casi el 75\% de ellas se concentran en bienes primarios (manufacturados o no).

De 2007 a 2010, la matriz de competitividad relacionada con la OCDE se modificó radicalmente. En particular, las exportaciones en situación de oportunidades perdidas representaron casi el 43\% del total y, las que se encontraban en situación óptima, el 29\%. Sin embargo, esta transformación en el formato de la matriz no deriva de variaciones sustanciales en el patrón de exportaciones de la Argentina, sino del hecho de que la demanda de bienes primarios y alimentos pasó a ser dinámica en ese subperíodo. Este es otro ejemplo de que la demanda de bienes relacionados con los recursos naturales por parte de la OCDE no evidencia una tendencia decreciente. Los peores resultados relativos al destino OCDE también se observan en la década de 1990, lo que deja en evidencia la fragilidad del patrón de inserción externo argentino durante el Plan de Convertibilidad.

En lo que se refiere al MERCOSUR, la matriz de competitividad muestra que, durante la mayor parte del período examinado, alrededor del 50\% de las exportaciones estaban en situación óptima, y casi tres cuartas partes correspondían a grupos dinámicos (con una participación mayor de esos grupos de 2007 a 2010). De lo anterior se exceptúa el subperíodo 2000-2007, cuando las exportaciones en situación óptima eran apenas el 17\% del total y, las dinámicas, el 46\%.

Es muy probable que, entre 2000 y 2007, el marcado aumento de la demanda de manufacturas no basadas en recursos naturales por parte del MERCOSUR no haya sido absorbido por la oferta de la Argentina, debido al gran incremento de las exportaciones en situación de oportunidades perdidas, que pasaron del 12\% en 1990 a casi el 29\% en 2007. Esto revela las dificultades que hubo en el país para adaptar la estructura industrial y la oferta exportable a la demanda creciente del mundo y del MERCOSUR a inicios del siglo XXI. En efecto, luego de una década de destrucción del entramado industrial nacional, en que casi la totalidad de las exportaciones correspondieron a grupos vulnerables, las posibilidades productivas para atender la demanda nacional e internacional fueron reducidas. En ese período, otros países competidores ganaron espacio en el MERCOSUR y se lo quitaron a la Argentina. De hecho, el Brasil ganó espacio con relación a la Argentina y, desde 2000, China es el principal rival de ambos países (Fernández, 2014, pág. 77).

Finalmente, en lo que respecta a los países en desarrollo de Asia, la matriz de competitividad se caracteriza por la elevada composición de las exportaciones en grupos en que la Argentina es competitiva. La composición se mantuvo casi idéntica en los dos primeros períodos analizados, cuando los grupos vulnerables superaban a los que se encontraban en situación óptima y juntos concentraban más del 80\% de las exportaciones. En el período 2000-2007, más del 90\% de las exportaciones argentinas se concentraron en esos grupos, aunque el orden se invirtió. No obstante, el subperíodo 2007-2010 se caracterizó por una fuerte expansión de las exportaciones en situación de oportunidades perdidas, que absorbió una intensa reducción de las exportaciones en situación óptima. Los grupos poco dinámicos (vulnerables y en retirada) fueron preponderantes hasta 2000, aunque mantuvieron una tendencia decreciente y terminaron representando apenas el $18 \%$ de las exportaciones en 2010. 


\section{Reflexiones finales}

En este artículo se analizó la evolución del patrón de exportaciones de la Argentina de 1985 a 2010, a través de la matriz de competitividad de Fajnzylber y Mandeng, y se destacó la relevancia de los recursos naturales en los datos históricos de la región. Los mercados analizados fueron el mundo, la OCDE, el MERCOSUR y los países en desarrollo de Asia.

En el estudio se concluyó que la composición de la demanda del mundo y la OCDE se mantuvo prácticamente idéntica. Incluso es notable que la participación de la OCDE haya disminuido sin que las semejanzas entre las estructuras de importación se hayan borrado. Los datos son elocuentes. En 1985, las importaciones de la OCDE representaban el 83\% de las importaciones mundiales y, 25 años después, todavía alcanzaban más del 64\%. Es decir, la demanda mundial fue y sigue siendo muy estimulada por la demanda de los países industrializados. Ese fue el motivo por el que Fajnzylber y Mandeng analizaron exclusivamente la demanda de la OCDE.

Ahora bien, los países en desarrollo de Asia han ganado espacio entre las importaciones mundiales: absorbieron parte de la reducción de la OCDE y su participación se duplicó ampliamente, hasta alcanzar el 25\% de las importaciones del mundo en 2010 (Fernández, 2014). Esto no había sido sugerido por dichos autores.

En este aspecto, es singular que, aunque la estructura de la demanda de la OCDE y de los países en desarrollo de Asia haya mejorado desde 1985 en favor de las manufacturas no basadas en recursos naturales, la estructura de las exportaciones argentinas hacia esos mercados no haya evolucionado en ese sentido. Paradójicamente, como resultado de la influencia de los países en desarrollo de Asia, se habría reforzado la primarización del patrón de exportaciones argentino. Y aunque hasta 1990 casi la mitad de las exportaciones argentinas a dichos países consistía en productos manufacturados de alto valor agregado, esa posición no se logró consolidar en las décadas siguientes a la implementación exhaustiva del consenso de Washington y el Plan de Convertibilidad.

Lo opuesto sucedió con las exportaciones al MERCOSUR. Hubo una clara y expresiva reducción de la participación de los recursos naturales y la energía en la estructura de la demanda de dicho mercado. El mismo cambio estructural ocurrió en la matriz de exportaciones hacia él: las manufacturas no basadas en recursos naturales cobraron mucha relevancia. En otras palabras, la demanda de productos de mayor valor agregado proveniente del MERCOSUR ha tenido un impacto directo y positivo en las exportaciones argentinas.

Aunque históricamente la inserción internacional argentina haya estado vinculada a la demanda de recursos naturales y alimentos proveniente de los países industrializados (cuya demanda decreciente fue observada por Fajnzylber en 1991), podría afirmarse que en la actualidad son los países en desarrollo los que juegan un papel determinante en la reconfiguración del comercio internacional, y, por lo tanto, del patrón de exportaciones argentino. Los datos mostraron que la demanda de los países en desarrollo de Asia acentuó la primarización de la inserción externa argentina, y que la demanda de la OCDE no viene favoreciendo el desarrollo industrial de la economía del país. Por el contrario, el MERCOSUR fue un factor determinante en la mejora del patrón comercial argentino. 


\section{Bibliografía}

Balassa, B. (1965), "Trade liberalization and 'revealed' comparative advantage", The Manchester School, vol. 33, N², Wiley.

Bielschowsky, R. (1998), "Cincuenta años del pensamiento de la CEPAL: una reseña”, Cincuenta años de pensamiento en la CEPAL: textos seleccionados, Santiago, Comisión Económica para América Latina y el Caribe (CEPAL)/Fondo de Cultura Económica.

Castro, C. (2011), "Cooperación, internacionalización temprana y organización empresarial en América Latina: el caso de la Organización Techint”, Investigaciones de Historia Económica, vol. 7, № 2, Madrid, Asociación Española de Historia Económica (AEHE).

Fajnzylber, F. (1991), "Inserción internacional e innovación institucional”, Revista de la CEPAL, N 44 (LC/G.1667-P), Santiago, Comisión Económica para América Latina y el Caribe (CEPAL).

(1988), "Competitividad internacional: evolución y lecciones", Revista de la CEPAL, N 36 (LC/G.1537-P), Santiago, Comisión Económica para América Latina y el Caribe (CEPAL). (1983), La industrialización trunca de América Latina, Ciudad de México, Editorial Nueva Imagen.

Fernández, V. (2014), "A inserção externa da Argentina: um estudo sobre a relevância dos recursos naturais no padrão de exportações, a competitividade e o comércio intra-industrial, no período de 1985 a 2010”, tesis, Curitiba, Universidad Federal de Paraná.

Ferrer, A. (1973), La economía argentina: las etapas de su desarrollo y problemas actuales, Ciudad de México, Fondo de Cultura Económica.

Furtado, C. (1964), Desarrollo y subdesarrollo, Buenos Aires, Editorial Universitaria. _(1962), Formación económica del Brasil, Ciudad de México, Fondo de Cultura Económica.

Latin American Perspectives (2015), vol. 42-6, № 205 [en línea] http://latinamericanperspectives.com/2015/11/.

Magee, S. (ed.) (1975), "Prices, incomes, and foreign trade", International Trade and Finance: Frontiers for Research, P. B. Kenen (comp.), Nueva York, Massachusetts, Cambridge University Press.

Mandeng, O. J. (1993), "Análisis de competitividad: Argentina. Estudio de caso basado en el programa computacional CAN", Indicadores Econômicos FEE, vol. 21, N² 2.

(1991a), "Competitividad internacional y especialización", Revista de la CEPAL, № 45 (LC/G.4687-P), Santiago, Comisión Económica para América Latina y el Caribe (CEPAL).

(1991b), "Metodología para un análisis de la competitividad internacional de los países", Industrialización y Desarrollo Tecnológico, vol. 10, Santiago, Comisión Económica para América Latina y el Caribe (CEPAL).

Pinto, A. (1960), "Estabilidad y desarrollo: ¿metas incompatibles o complementarias?", El Trimestre Económico, vol. 27, N¹06(2), Ciudad de México, Fondo de Cultura Económica.

Prebisch, R. (1952), Problemas teóricos y prácticos del crecimiento económico (E/CN.12/221), Ciudad de México, Comisión Económica para América Latina y el Caribe (CEPAL).

(1949), El desarrollo económico de la América Latina y sus principales problemas (E/CN.12/89), Santiago, Comisión Económica para América Latina y el Caribe (CEPAL). 